

\section{'}





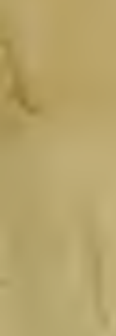




\section{P. ITE I.}

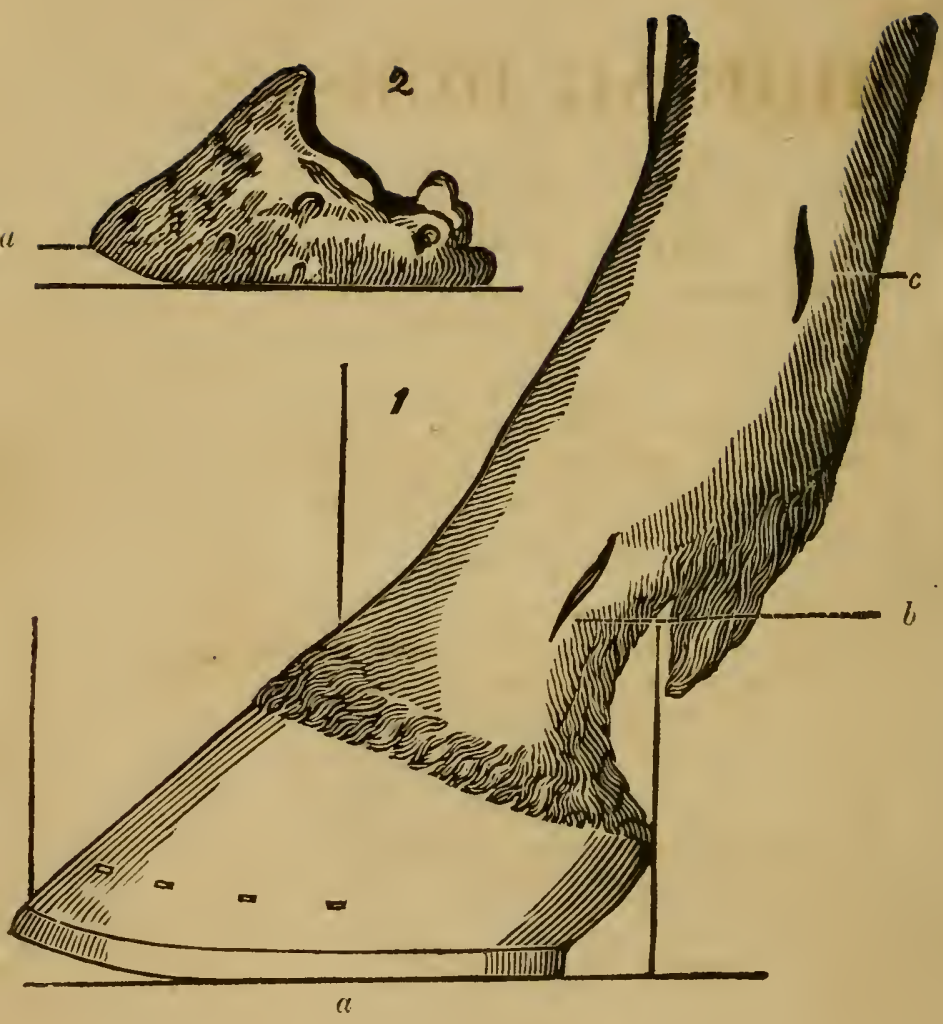




\section{H.bodrman;}

A

\section{NEW SYSTEM}

\section{OF \\ SHOEING HORSES,}

ABRIDGED FROM THE WORK OF

\section{JOSEPII GOODWIN,}

Veterinary Surgeon to his Majesty Geo. IV., and Member of the Royal College of Surgeons.

\section{CONTANING}

A CONPARISON BETWEEN THE ENGLISH AND FRENCH METHONS, AND OBSERVATIUNS ON THE DISEASES

OF THE FEET CONNECTED WITII SHOEING.

To which are added,

BSERVATIONS ON RLEEDING AND THE PULSE, A CONCISE

VIEW OF THE ANATOMY OF THE FOOT, NotEs, REMARKS, \&c.

By JOHN B. BROWN, M. D. M. M.S.S.

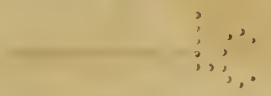

BOS'TON :

PRINTED BY WELIS AND LILLY.

1821. 


\section{SF907 G65 \\ 1821}

$\therefore \vdots$ 


\section{PREFACE.}

The Editor of this abridgment, has no other object in its publication, than to meliorate the condition of that very useful animal, the Horse, by presenting to the American public Mr. Goodwin's New System of shoeing. Mr. G.'s original work upon this subject is expensive ; and if republished in this country, probably would not be generally read by those who might be most benefited by it. It has therefore been thought advisable to abridge it. In 
this abridgment the editor has been careful to select every thing, necessary to give to the mechanic, a full and practical knowledge of Mr. Goodwin's principles and method of shocing, and it is believed, that it contains information, which will compensate any one who feels an interest in the horse, for a careful and attentive perusal.

A circumstance very favourable to the adoption of this new system of Shoeing, is that there can be no danger of injury to the foot, from the change, if the shoe be properly put on, however long the horse may have becn shod according to the method usually adopted in this country. The principal alteration necessary to be made in the form of the hoof is, at the toe, which is usually thick, and not very likely to be injured by any one tolerably 
acquainted with the anatomy of the parts. A bad workman may bring disgrace upon any system of shoeing, or any other mechanical operation, however good it may be in itself, when properly executed.

The editor of this abridgment does not take upon himself the responsibility of recommending Mr. Goodwin's system of shoeing horses, nor will he feel himself in any degree implicated in its success. He presents it to the public, as it is, and the public will judge and determine whether it be an improvement upon our present method of shoeing, or not. If no attempt be made to improve, certainly no improvement can be expected. Whatever the opinion of the reader may be with regard to the particular method of shoeing recommended by the author, it is believed that he will find the work itself to contain much useful 
information, relative to the subject on which it treats; and it is hoped that its publication, here, will serve a useful purpose. 


\section{CONTENTS。}

Chap. I......... Of Contraction . . . . . . . . . 1

Chap. II........ Th Thush . . . . . . . . . . 11

Chap. mis...... Cof Corns . . . . . . . . . . 16

Chap. Iv...... Of Sand Cracks . . . . . . . . . 21

(iHaP. v......... Of Pumiced Feet or Convex Soles . . . . 24

(iнap. VI....... Soles Unnaturally Concave . . . . 33

(iha P. vil.... Of Founder . . . . . . . . . . . . 36

(:HaP. vill...On the Nerve Operation. . . . . . . . 40

CHAP. IX..... Of the French System . . . . . . . 50

CHAP. X.......Mr. Goodwin's System . . . . . . 56

(HaP. XI...... On Bar Shoes . . . . . . . . . 69

CHap. XIr....On the Patten Shoe . . . . . . . 74

Ghap. XIII...On Screw Shoes . . . . . . . . 77

Chap. Xiv...On Fullering . . . . . . . . . 82

ChaP. Xv.... On Punching . . . . . . . . 84

C'HAP. Xvi...On Frosting . . . . . . . . . . 88

CHAP. XVII..Of Nails . . . . . . . . . . . 92

CHAP. XVIII.On Nailing . . . . . . . . . 97

Chap. XIX.. Observations on Blood-Letting. . . . . 107

Crap. Xx......A Concise View of the Anatomy of the Foot . 132

Explanation of the Plates . . . . . . . 137 

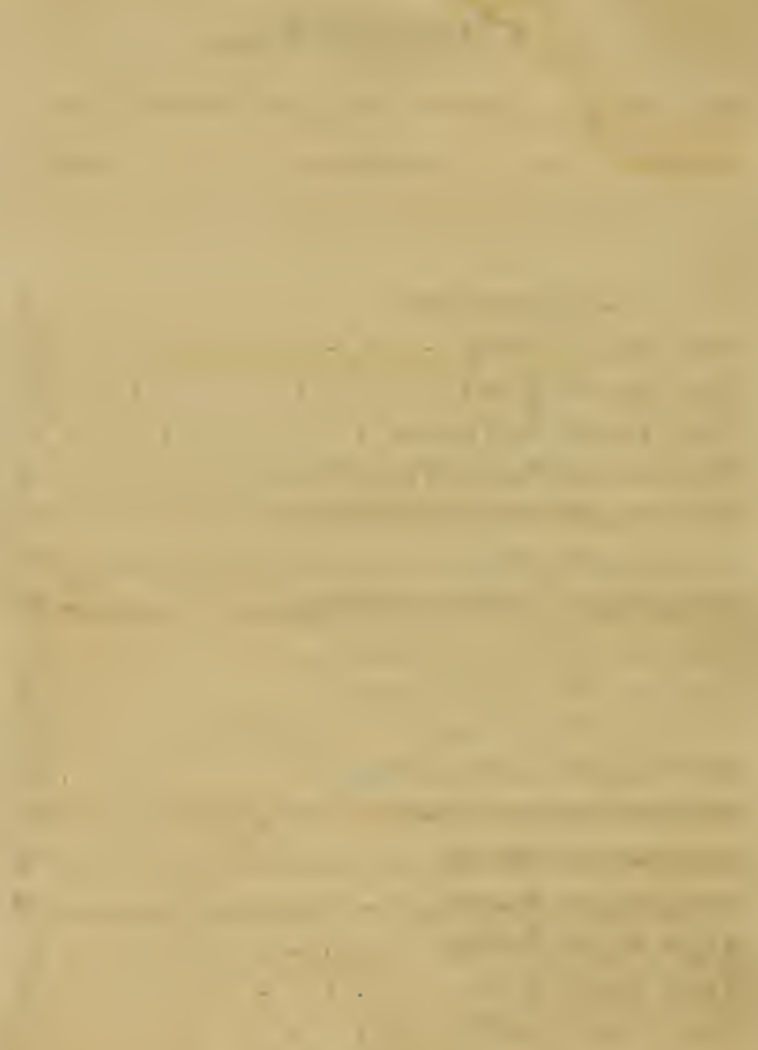

1

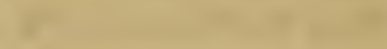

I 


\section{CHAP. I.}

\section{OF C ONTRACTION.}

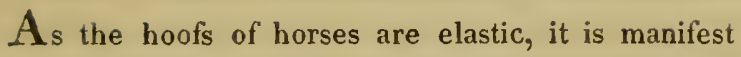
they must be susceptible of changes. Contraction is every where to be observed among horses in this country, and it is a rare occurrence to meet with feet, that have not partaken more or less of this prevailing disease.

The state of the foot is observed in a variety of forms; sometimes, it is perceived that both heels are approaching near together, and that the space appropriated for the frog, and the frog itself, is diminishing in its diameter; the frog also becomes ragged, dwindles away, and has little or no horn; 
the quarters and heels at the same time lose their shape, and finally, the foot becomes larger round the coronet than at the base. In some cases it is seen that one heel is inclined to contract more than the other, and this happens more frequently with the inner quarter and heel than with the outer.

In other cases contraction begins at the coronet, and as the hoofs grow down, there appear many leep grooves round the foot; the soles are generally thick, and the quarters and heels high;-the term, high, is rather an improper one, but it originates in the horse being raised in consequence of the descent of the heels below the frog.

As the sides or quarters come nearer together, the foot increases in length at the toe, and frequently assumes the appearance of a mule's foot--Contracted hoofs are generally dry and hot, which may be ascertained by comparing with the hand the heat of a contracted hoof with the heat of a perfect one. Let a contracted hoof be immersed in water, and also another which is not contracted; it will then be seen that the contracted foot dries much sooner than the other.

Horses that have an abundance of horn are more prone to this disease than those where horn is in a 
less proportion; but it occasionally affects all denominations of hoofs.

On the first appearance of this disease, a horse is continually changing the position of his feet in the stable ; thus evincing more or less internal inflammation, and on pressing the soles with pincers he flinches. He tirst advances one leg and then the other, if the disease be in both feet; but if one only be affected, it is invariably that which is stretched forward.

When required to work, he sweats much sooner than a sound horse, he goes near the ground, is afraid to lift his feet up, appears foot-sore, tender, and goes very unsafely; he frequently trips, blunders, and ultimately falls. In this manner the disease goes on till the horse becomes permanently lame.

If the contraction be in one foot, that soon becomes smaller than the other; and if in both, they both diminish in size.

It is distressing to witness the action of horses in this state; the pain they endure induces them to throw as much weight on their haunches as they can in order to relieve their fore-feet; they consequently stretch out their fore legs, bend their hocks? 
and lower their croups nearer to the ground. When in the stable they continually lie down, and will scarcely get up to feed; in this deplorable state, and it is lamentable to know that it is frequent, the animal is doomed to the slaughter-house.

In the early stage of this disease, various attempts have been made to relieve it, as drawing the soles, which is a cruel and barbarous operation, and often has a tendency to aggravate instead of to mitigate the symptoms; blistering and firing round the coronet, removing the contracted parts, grooving with a drawing-knife in various directions, and turning out into marshy places until the hoofs are grown down again, and a variety of other expedients. In some instances, when taken up from grass; the feet appear better, and the horse again returns to work; but in most cases this is of short duration, and then, if in the country, he is sold for a stage-coach, or for post work; or if in London he is sent to a repository, where he is sold for a stage or a hackney coach, and in this way he lingers out a life of pain.

It is not unfrequently seen, that this disease takes place at an early age, and produces lameness; on the other hand we occasionally observe an old horse with his feet contracted, and otherwise out of 
shape, who is nevertheless very sound, but in the majority of cases, lameness takes place at the commencement of the disease.

This disease is commonly known by the term groggy, founder, \&c., and when the hoofs are not much deformed, it is called chest founder, and it is generally considered to be seated in the chest.

The hind-feet of horses are not liable to this disease, or, perhaps, speaking more properly, they do not suffer from the effects of it : we occasionally see the hind-feet of a bad form, but I never yet saw a horse labour under any permanent lameness in the hind-feet, similar to what has been described respecting the fore-feet.

There are several causes which contribute to bring on contraction; but there is no one which has come within my observation that is so clearly manifest as the mechanical effects of the present modes of shoeing.

If we consider that the hoofs of horses are elastic and yielding, and that iron is a solid unyieiding body, we may readily conceive when an elastic body is bound on, or nailed to an inelastic one, if there be much action or motion, or much weight to support, that the yielding body will give way, and conse- 
quently that the horn of the foot must be continually undergoing a change in its form, which I contend is occasioned by the shape of the English shoe now in common use. Having stated that the foot surface of the shoe is invariably a plane inclining from the outer to the inner edge, and that the ground surface is convex, and also that a piece of solid iron of the form described is nailed on to the hoof, it necessarily follows, as the horse treads on the shoe which is convex on the ground surface, that the whole weight must be supported on an edge, and by the nails and clinches. Thus the weight of the animal is continually squeezing the sides of the hoofs together; and all the horn, at the quarters and heels behind the last nails, has no power to prevent the weight above from pressing them down the inclined plane.

To exemplify this idea, suppose a horse's foot to be put into the mouth of an iron box the size of the foot, and of a conical shape, and that it is pressed by a heavy weight; the iron box being of an unyielding substance, and the hoof elastic, it must, by degrees, assume the form of a cone. Now this is precisely the principle of English shoeing, and it is evident that the base, or bottom of the foot, is gradually made less and less, and becomes variously distorted in its form. 
Some are of opinion, that if horses were shod by the worst of smiths, and were not allowed to come into a stable, but were kept at grass, that their feet would not contract or undergo any change in form, but would remain sound. Unless these horses were kept at regular work on pavements or turnpike roads, no fair conclusion could be made from such an experiment; it is probable, however, that lameness might thus be diminished in the same proportion as the feet are injured by confinement in the stable; but still the animal would be subject to all the bad effects of an ill-formed shoe.

Another cause of contraction is found in the heat of stables, and more particularly in the litter being: allowed to remain too long in the stalls. The ordinary custom of stablemen is to remove the wet and heated part of the litter from the stalls twice a week, but in many instances only once, which, being soaked in urine and dung, soon ferments and forms a complete hot-bed. This has a powerful effect on the hoofs of borses; and the contrast of a state of nature, and of a bed so heated, must be very obvious.

There is also another cause which materially contributes to the production of this disease, which is the bad mode of paving the stalls of stables so 
much higher before than behind. When stables are constructed, this circumstance is too frequently left to the discretion of architects. It must be evident, that in stalls paved in this usual manner, the weight of the animal is thrown very unequally on the fore legs and feet, with the toes up much above the heels; the horse being compelled to stand in this strained position, his weight is irregularly distributed, and the bad effects are soon discorered, not only in the tendons and ligaments, but even in the feet themselves.

Much has been said about paring the frogs and cutting out the bars of the hoof, as having a powerful effect in producing contraction, and strong injunctions have been given, that they should not be touched by any instrument. It has not, however, come within my observation, that if the frogs and bars are pared with discretion, that any tendency to produce coniraction is occasioned by it; on the contrary, I cons.der it to be necessary.

Contraction appears to me, in some instances, to be a cause of inflammation, and in others to be an effect. In the first instance this is demonstrated by a manifest alteration in the form of the foot previous to lameness; in the latter instance, lameness pre- 
cedes, for some time, any change in the form or appearance in the hoof.

Another cause of contraction may be added, which is the great concussion the feet receive when going fast over pavement or gravelled roads; this inclines them to inflammation; and contraction, in these cases, must be one of the consequences.

Contracted feet, when dissected, exhibit a variety of diseased appearances: in some instances considerable ossifications and anchylosis of the joints; and in others, the bones within the hoofs have lost their solidity, and have become spongy from the absorption occasioned by the great pressure from the contracted horn.

I have before observed, that various expedients have been resorted to for the relief of contraction and its effects; but I consider it of much greater moment to suggest a method of shoeing calculated to counteract so prevailing and so destructive a disease; and I trust I shall not be considered too sanguine in conceiving, that after a long perseverance I have arrived at something like such a result.

With regard to the treatment of this disease, on the first appearance of contraction, bleeding both generally and locally to counteract inflammation 
ought to be employed, and the veins which ramify over the cartilages of the coffin-bone will afford a plentiful local evacuation; purging, spare feeding, the abstraction of heat by the application of moisture, and the plan of shoeing subsequently recommended, appear to me calculated in some instances to cure this disease, and in most cases to relieve and to mitigate the symptoms.

NotE.-Sore smiths are in the habit of opening the heels, in cases of contraction, by notching the bars and crust. This is a jockey's trick. It gives to the foot an open appcarance, approaching towards a natural form, but the effect is merely temporary. As soon as the horn grows down, the hoof will assume its contracted sliape,-AMERICAN EDITOR. 


\section{CHAP. II.}

\section{OF TH R U H.}

The Thrush, a very common disease, makes its appearance in the cleft or centre of the frog. A sound frog is full of horn, and is firmly united in all its parts; but on the appearance of a thrush it is separated in the cleft, making a complete division of the horn, and penetrating through its whole substance to the sensible frog (which is the seat of this disease), where its depth is terminated. Inflammation and suppuration take place in the sensible frog, and a discharge of foetid matter, more or less, according to the state of the disease, issues through the division of the horn in the frog. This division often extends as far back as 
the hair of the heels, but seldom further forwards than the cleft of the frog.

The thrush is found in all horses: sometimes in one foot only, on other occasions in both fore feet; though the disease is more frequent in the hind than in the fore feet. If it be allowed to continue long, the frog begins to diminish in size; it grows ragged and uneven on its surface; it loses the tough and elastic property of the sound frog, and becomes dry, hard, and brittle ; eventually little or no horn is produced, and the whole frog is a mass of filth and disease. As the disease advances, the heels and quarters close in nearer and nearer together, and the space which nature appropriated for the frog becomes nearly obliterated.

Thrushes appear principally to arise from two causes, viz. the effects of the present mode of shoeing, or continued exposure to moisture.

In some cases a thrush produces lameness, but most frequently it is unaccompanied by it. This circumstance has produced a great variety of opinions as to the soundness of horses in this disease; and it has long been disputed, whether the horse is to be considered sound or unsound. There are certainly a great number of horses with thrushes, 
where the hoofs have not undergone any material change in their form, that $\mathbf{l}$ should not hesitate to pronounce sound; but if a thrush be accompanied by a change in the form of the foot, I should pronounce the horse to be unsound.

Any plan of shoeing which is calculated to bring on contraction, is the most likely to cause thrushes. It has been insisted upon by modern authors, that a principal cause of thrush is the constant practice that smiths adopt of paring the frogs previously to shoeing. This, like most things carried to an extreme, is, no doubt, injurious; but if it be done with judgment and discretion, I consider it a necessary and useful practice. For as the foot is continually growing, the exterior parts, in time, become dead, and separate from the horn growing underneath; if, therefore, these exuberant and extraneous parts be not occasionally removed, a collection of dirt and filth is found between the growing and the dead horn, which, if suffered to continue, frequently terminates in a thrush. But if these extraneous parts are removed with judgment, I have always found that the practice is beneficial.

There is one unerring criterion for the smith's direction in the performance of this operation. When 
the dead horn is removed from the frog, he will invariably find a whitish, mealy, and crumbly appearance, where the growing horn separates from that which is dead; all, therefore, that the smith has to attend to is to pass through this crumbly or mealy appearance, and to show the face of the growing horn; but on no occasion to remove it.

The cleft of frogs, or the seat of thrushes requires this attention perhaps more than any other part of it: the operation cannot be effected with any accuracy with the smith's sole-knife; it requires a smaller one, with a larger turn, which is better adapted to clear out the cleft and the sides of the frog. .

If there is much discharge, a few dressings in the cleft with a little Ægyptiacum, or tincture of myrrh, and a small proportion of vitriolic acid will be useful. Afterwards a piece of tow saturated with a dressing of equal quantities of tar and hog's lard may be put into the cleft daily.

When horses have been long at grass, or kept in wet places without due attention to their feet, thrushes are often the consequence. In these cases it will be necessary to remove all the ragged parts of the frog, and to apply the dressing before mentioned, which in most instances will succeed. In all cases great attention to cleanliness is necessary. 
The cause of thrushes, in the hind-feet of horses which are kept in stables, is the continued application of moisture from dung and urine.

It is a general observation, that it is hazardous to stop a thrush; for by so doing it will affect the eyes. If the disease has existed long, it may be advisable to bleed and physic, as a continued drain from any source requires some precaution when stopped.

Neglected thrushes sometimes terminate in canker; but that is a disease which I do not consider as strictly connected with those which are occasioned by the present system of shoeing. 


\title{
CHAP. III.
}

\author{
OF C OR N S.
}

$C_{\text {onns are a very trequent disease, and common to }}$ all horses; but those accustomed to slow work are less liable to it than any other class. The hind-feet are not subjects to this disease, though on some occasions, a very trifling appearance of a corn shows itself in them; but cases of this kind are very rare, and I have never seen the bad effects produced by corns in the hind-feet, which usually attend that disease in the fore-feet.

Corns generally appear in the inner heels of the fore-feet, at the angle between the bars and the crust; and they seldom occur on the outside heels.

On removing the superfluous horn, corns show 
themselves by a reddish appearance of the horn in the part before named, and if a little more horn be taken away, they will be seen more distinctly, resembling a part bruised and full of blood, which has made its way into the pores of the horn. This appearance sometimes predominates in the direction of the bars, and sometimes between the crust and the sole, taking the direction of the laminæ.

Corns, like thrushes, are not always accompanied by lameness, though that is a very frequent and troublesome consequence of them.

It is als,o in this disease a disputed point, whether a horse is to be considered sound or unsound. Corns frequently appear at a very early age, and in some instances before the animal has been shod; if, therefore, every horse was deemed unsound that has an appearance of a corn, there would be very few that could be called sound. I consider this in a similar light to thrushes; if there be only the appearance of a corn, without any material change in the form of the hoof, or previous lameness, I should not hesitate to pronounce him to be sound; but on the contrary, if there be a difference in the form of the foot, and if he expresses soreness when pressed by a pair of pincers, I should then consider him to be unsound. 
It may be opposed to this, that when a disease has shown itself, the horse is no longer to be considered sound; but I think a necessary distinction may be made where there is only a trifling appearance of disease, without any ill effects, and when this appearance often gradually disappears.

When lameness proceeds from corns, it on some occasions comes on suddenly, but generally by degrees. When a horse is lame, and there is no reason to suspect it to be in any part above the foot, on the shoe being removed, it is often found to be occasioned by corns, and this the drawing knife and pincers soon ascertain.

Corns appear to be the effect produced either by the shoe, or by the horn taking a wrong direction in its growth. The consequence in both cases is the same; but the proportion of those which arise from the former cause, are infinitely more numerous than the latter, viz. an increased pressure from the shoe on the internal sensible heel, which causes an extravasation of blood into the pores of the horn; and if the pressure is continued, and there is more blood extravasated than can be readily taken into the circulation again by the absorbent vessels, inflammation and suppuration generally succeed. 
In some instances where corns have not been suspected to exist, and the horse has been lame for some time, it is found that matter has formed under the horn, pervading the sole and frog. This matter often makes its way up the laminæ, and ultimately breaks out between the hair and hoof, and terminates in an unhealthy sinus, or in what is termed a quittor.

It has been contended, that the only cause of corns, is from the heel of the shoe lying in close contact with that part of the sole which is between the bar and the crust; and that if a necessary portion of horn was removed at every shoeing, no such effect could occur; but, however cautiously this operation may be performed, if the shoe itself is of such a form as may produce a morbid change in the form of the hoof, it will be found that corns, with all their troublesome consequences, will continually take place. And I have no doubt, if a plan of shoeing can be suggested which is calculated not to bring on this disease, that it will be considered of far greater importance than any remedy which may be suggested for its cure.

To remove any urgent symptoms, if the horse is very lame, most likely suppuration will have taken place, and it will be proper to pare the horn as 
closely as the sensible parts will allow, that the matter may escape. Fomentations and poultices will be necessary, with bleeding and physic, and a spare diet; and as the inflammation abates, and the new horn grows up, any simple dressing may be applied.

It is sometimes a practice on the appearance of a corn, to apply caustic applications, and even the actual cautery; but it is obvious, that such a mode can only tend to aggravate instead of to alleviate the symptoms. If it has been necessary to remove much horn, the animal should be at rest, either in a loose place, or be turned out to grass, till the horn be regenerated. But, on some occasions, where horses are required to work before the new horn is grown down again, bar shoes will be of great use.

There are a number of cases where the inflammation does not terminate in suppuration, and where it has not been requisite to remove much of the crust: these symptoms are in general removeable by the ordinary treatment of inflammation, both general and local.

In all cases of lameness rest in a loose place is necessary. 


\section{CHAP. IV.}

\section{OF SANDCRACKS.}

T ${ }_{\text {HE Sand Crack is a longitudinal slit, or division of }}$ the fibres of the crust, which commences at the coronet, and extends more or less down the foot in the direction of the fibres, according to the previous state of the hoof; on its first appearance, it is seldom lower than the middle of the foot, and it is generally accompanied by a trifling discharge of blood, which may be perceived oozing through the crack.

The inside quarters of the fore-feet are most frequently the seat of this disease : it is seldom found on the outside quarters, and is rarely to be met with in the hind-feet.

All horses are liable to this disease, though some are more so than others. Those of the heavy 
kind, employed in slow work, are least liable; and the same reasons will apply here, as in contraction; for as this class of horses is generally used in slow draught, the heels are but little used; neither are they subject to a high temperature in the stable, nor accustomed to stand on hot litter.

This disease also is not always, though it is frequently, attended by lameness.

The cause generally arises from an improper method of shoeing; for that mode, which alters the natural form of the hoof, combined with the absence of moisture and the heat of the stable and litter, by destroying the tough elastic property of the hoof, renders it consequently more liable to this disease.

But it sometimes occurs among those that are never shod; for I have observed it among brood-mares without shoes; with them it generally happens in dry summer months.

If this disease be not radically removed, the horn will not re-unite; but will continue to grow down with the split still existing. The part separated is called is false quarter.

To effect a cure it will be necessary to cauterize the hoof at the coronet with a common firing iron, in a transverse direction, making a line across the 
crack of two inches in length, about an inch below the termination of the skin, the edge of the iron should pass through the horn to the sensible parts, and the surface of the coronary ring should be lightly cauterized with the flat side of the iron, to cause inflammation. The iron should also be applied at the lower end of the crack to prevent it extending further down.

A bar shoe should be employed, that the quarter and heel may not come in contact with the shoe, and to leave the diseased parts at rest.

This operation will of course produce considerable inflammation; the usual remedies of bleeding, physic, fomentations, poultices and a spare diet will then be necessary. When the inflammation is abated, the new horn, connected in its fibres, will be seen growing from the coronet, and the hoof will gradually become sound; a run at grass, or a loose place, will be beneficial until the new horn is completely grown; and when the horse is again shod for work, a different plan of shoeing, and keeping the foot cool and moist, are remedies which will naturally suggest themselves to prevent a recurrence of the disease. 


\section{CHAP. V.}

OF PUMICED FEET OR CONYEX SOLES.

[PLATE II. FIG. III.]

A PUMrCED foot is that in which the sole descends below the crust; if the horse stands without shoes, the sole is the part which will come in contact with the ground instead of the crust.

This disease is invariably accompanied with a deformity of the crust in the front of the foot; it loses the full and prominent appearance observable in a sound hoof, becomes hollow and wrinkled, and turns up at the toe. It is a very common disease, and all horses are liable to it; but it prevails principally among those which have flat, circular, broad feet. 
There are, however, cases of this disease in feet, where there is an abundance of horn.

As the disease goes on, the soie sinks lower and lower, the wrinkied hollow appearance in the front increases, and the toe curls more up, till at last the whole hoof becomes compietely distorted.

This disease, like some others, is not always accompanied by lameness. Horses with this sort of feet, when in action throw the greater part of their werght on the heels, consequentiy they seldom or ever trip, but are continually dropping and biundering.

The principal cause of this disease is a defective production of horn in the sole, crust, and laminæ; the frog and heels, generally are much stronger than the other parts; it rarely occurs until the horse has been shod some time, and I think it is inuch accelerated by the mode of shoeing now in practice.*

In horses where the secretion of horn is insufficient to meet all the purposes required, (and my observations lead me to estimate their number at about one balf,) it is found, even at in early age, after

* Mr. G. alludes here to a mode of shoeing, similar to the one now practiced in this part of the United States,-A. ED. 
having been shod a few times only; for as the crust and laminæ are thin and weak, they are unequal to support the weight, which nature intended should, from the peculiar structure of the horny and sensible laminæ, be chiefly borne by them. This does not wholly arise from a defect of nature, for nature did not intend that the animal should be shod, kept in liot stables, or go a great pace upon hard roads. As the disease increases, the coffin bone and the internal contents of the hoof, sink and bear down upon the horny sole, which, being also thin and weak, gives way, soon losing its concare appearance, and becomes convex. It is not unfrequent also, to observe a considerable separation between the sole and the crust, which in some cases extends upward, towards the coronet; the heels also take an oblique; shelving direction forward.

When a horse is in a state of nature, and on a yielding soil, the crust penetrates the earth, and a considerable portion of weight is consequently borne on the frog and sole, which shows that the crust and laminæ in this state have not so much to support as when the animal is shod. There is consequently, when shod, a double task imposed upon the crust and laminæ; when this is considered, together with 
the weak state of the horn, we are not much at a loss to account for the numerous feet we observe unequal to support the animal, and the deplorable effects arising from such a state of disease.

In the early stage, the crust which is in contact with the shoe is unequal to support the weight of the animal, it gives way, bends, and generally curls inwards at the quarters and heels, and not unfrequently rests on the sole, thereby causing lameness.

When the feet are not properly pared, but are allowed to spread (which they are generally disposed to do,) they become large, broad and flat at the bottom; and unwieldy and clumsy when in action.

Horses of this description, if going over pavement, may generally be distinguished by the hollow clattering noise produced by the broad heavy shoes they generally wear.

1 cannot omit this opportunity to mention the absurd instructions which on many occasions I have heard given to smiths, not to remove a particle of horn from the foot, because, it is said, nature never made any thing in vain. Those who give these orders must forget, that as the foot is covered with iron, and is continually growing, that no hom is removed, except by the smith, and that if it 
were allowed to remain, it would soon grow into a variety of distorted forms.

Another cause, which sometimes produces this disense, and sometimes occurs in the hind feet also, is "fever in the feet." This is by no means so common a cacise as those before described, but it is not an unfrequent one.

When the lisease takes place from this cause, it produces the most distressing effects, and in some instinces it prcceeds till the hoofs separate from the senzible parts and come off. On inspection after death, tive horny and sensible laminx, the coffin bone, and all the contiguous parts are found to be in a high state of disease.

To relare pumiced feet, the first thing necessary, if it procesds from a weak, feeble state of the hom, is to assist the crust and laminæ in supporting the siperincumbent weight by taking off the shoes and allowing the sole and frog to come in contact with the ground; thus in a great measure the weiglit will be taken off the crust and laminæ, and they will be in a comparative state of rest. All the superfluous horn should be removed, and if the case be severe, it is probable that the foot will be too sore and tender at first for the animal to stand on a 
hard flat surface without shoes; he should therefore have a plentiful litter of straw in a loose place, and the whole surface of the foot should be rubbed daily with tar and lard ointment.

If this plan of treatment be adopted, it will soon be observed that the prominent parts lessen in convexity, and an increased growth of horn at the coronet takes place. The crust and sole should be kept pared, so as to allow the foot to bear on the convex parts, thereby easing the laminæ and crust, and affording them sufficient rest to regain their usual strength.

As the bottom of the foot approaches to flatness, the horse will be able by degrees to bear the standing on a hard level surface several hours in the day. But as a level hard surface is not always to be obtained, a pair of foot boots will be very useful, and they can be used with very great advantage, as the bottom surface of the boot can be easily regulated. In the first instance, a piece of tow saturated in tar and lard ointment may be put into the bottom of the boot, which should be repeated daily, reducing by degrees the quantity of tow till a hard level surface is finally obtained, which is most congenial to the feet when they are able to bear it. 
The crust should be rasped down level with the sole, and the toes shortened every fortnight. Proceeding in this way, a tolerable foot may be obtained in time.

When horses are not worth much expense, the best course to be pursued is to turn them out for a few months, observing the directions to rasp the crust and shorten the toes.

If the disease is not too far advanced, the convexity may sometimes be entirely subdued, and the sole will even assume the natural concave form, though in most cases it inclines to flatness; nevertheless, liorses of this description, if properly shod, will work well and be effective. They in common require to be shod with a bar shoe, in consequence of the crust, from its weakness, bending and curling in different directions. If it curl inward it will generally press upon the sole, and if it bend outward, it is liable to break, and leave a breach in the crust. IVith a bar shoe, the weight of the animal is borne more equally on the whole surface of the foot, and the bottom of it is also greatly lefended.

There are many instances where horses have done their work well for years with bar shoes, and 
on trying if they would work in plain shoes, the result has invariably terminated in re-applying the bar shoes; much, however, depends on the manner in which bar shoes are put on, and I refer the reader to the chapter on that subject.

As many horses are compelled to work when this disease has made considerable progress, a broad heavy hollow shoe is applied, and some smiths, who perhaps work better than others, put on what they term a boxed shoe, which has a bar, and on the foot side a seat place for the crust to rest on; on the ground surface the nail holes are set down below the raised or hollow part of the shoe; by this means the convex sole is covered and protected from blows, or the pressure of stones and gravel, \&c. and if horses are shod when in this state, this is certainly the best plan; but when the soles become so convex as to require expedients of this kind, a still better mode is to put the horse out of work for a time, and to employ the treatment here recommended, till he is able to wear flat shoes.

The application of a very narrow and thick shoe, for feet of this description, has been recommended by Mr. White of Exeter; but I think few persons 
would venture to ride a horse with thin soles, if shod in this way, on a road exposed to flints and stones; perhaps over pavement a horse with such a shoe might go better, make less noise, and be more secure on his legs, as he would not be so liable to slip or slide as be would be with the large flat shoe. 


\section{CHAP. VI.}

\section{OF SOLES UNNATURALLY CONCAVE.}

As the perfect hoof has a concave sole, I here refer only to those cases where the concarity is such as to be considered a disease. Instances of this kind are by no means so numerous as those where the feet are too convex, at the same time it is not an unfrequent disease.

It may readily be conceived that this disease will prevail among those horses which have an abundance of thick, strong, and firm horn. It never occurs in the hind feet.

In contracted feet the soles generally become too concave as the contraction increases, but that degree of concavity belongs particularly to cases of contrac- 
tion, and is quite a distinct disease from that which I am about to describe.

It occurs in those feet, where, if a person had no previous knowledge of the animal being lame, he would think it, on a casual view, a perfect, strong, and firm foot; but on knowing the animal to be lame, and observing no external cause, on a closer inspection, and by paring the foot, the cause of the lameness will soon be perceived to arise from an increased concavity of the sole, which will be found to be two or three times the thickness of an ordinary sole, and when thinned to a moderate degree, the bottom of the foot assumes the appearance of a hollow conical dish.

It not unfrequently occurs at an early age, as I have seen many instances of it at four years old; and it most generally occurs in hoofs of a circular form.

The symptoms of lameness in this disease very much resemble those of contraction; and the same expedients for the cure of it have often been resorted to, with no better success. This is also called groggy founder, \&c. The immediate cause of lameness arises from the horny sole losing its elasticity, and pressing the sensible sole against the 
coffin bone; so that the highly sensible sole becomes pinched and squeezed between two hard bodies, which produces great inflammation and pain every time the horse sets the foot to the ground. The predisposing causes are a superabundant production of horn, and the too prevailing stable-practice of standing on hot litter in an ill paved stall without any stopping. Thus the horn becomes dry, hard, and unyielding; and if an animal with this description of foot belongs to a gentleman, who directs his smith not to remove any horn, the disease will rapidly increase.

The most likely means to obtain relief are the expedients used in inflammation, keeping the feet cool and moist; and that these remedies may have a better effect, the soles should be pared very thin once a fortnight, and such shoes applied as are most likely to keep the foot expanded. When the disease has not existed too long, I have seen many cases cured altogether, but it is a troublesome disease to contend with, and the horses generally become fit only for slow draught.

If the causes which have been named, were avoided when young horses first come into stables, I am quite satisfied that the disease would rarely occur. 


\title{
CHAP. VII.
}

\author{
OF FOUNDER.
}

F ounder is a term often made use of to express different diseases of the foot, and is generally applied in those cases where the cause is not very evident. But there is one disease which more particularly comes under this denomination than any hitherto described.

When a horse has been lame for some time without any apparent cause, this disease is then generally supposed to exist. It prevails among all horses, and never occurs in the hind-feet.

I cannot give a better illustration of it than by relating the following case, which occurred in a very 
celebrated hunter. When I saw the horse, he had then been lame two or three years, and it had been supposed that he was merely tender or sore from some slight inflammation; but in spite of all the remedies that were adopted, the disease increased progressively until he became excessively lame, exhibiting all the distressing symptoms observed in severe cases of contraction. Various opinions had been formed as to the seat of the disease; as almost every part of the fore-legs, shoulders, and feet, bore the marks of a variety of operations which had been performed; firing, blistering, rowelling, \&c. After having minutely examined into the nature of the case, my opinion led me to state that there was no prospect of relief, and that, notwithstanding the hoofs had every appearance of perfection, the cause of lameness would be discovered, on dissection, to exist in the foot.

The gentleman, to whom the horse belonged, inmediately directed that he might be destroyed, and after death sent me the feet for dissection. There was no reason whatever to believe, that any change of the form or structure of the horn was the cause of the lameness; but on prosecuting the dissection, I found that a considerable degree of ossification had 
taken place in the large flexor tendon, which passes over the navicular bone; adhesions also between the bone and the tendon; the articular cartilages very much ulcerated, and that the body of the bone had become carious. The disease in both feet was very nearly similar.

As this disease occurs in feet where no change of form has taken place to warrant any idea of its arising from such a cause, it can only be attributed to the violent concussions which the feet are subject to when in strong action, together with the heat of stables and standing on hot litter. These in the first instance produce inflammation, and as the animal is still exposed to the same causes, the inflammation goes on, and sometimes terminates in a complete anchylosis of the joints of the foot; if the inflammation be not soon arrested, its effects are generally such as to render the animal almost useless.

If this disease be suspected to exist, the animal should be kept in a perfect state of rest, by turning him into a loose place, taking his shoes off. Bleeding, both general and local, purging, and keeping the feet in water-boots, thinning the soles frequently, are remedies likely to subdue the inflammation. 
It is very manifest, that any plan of shoeing which is calculated to counteract the effect of concussion must be desirable; and I am quite satisfied from much experience, that the plan hereafter explained possesses this property in a great degree.

It may not be unworthy of remark, that much credit has been given to Mr. Turner, of Croydon, for having discovered the seat of this disease, which has been called the 'Navicular disease.' Though the case here mentioned was dissected before Mr. Turner became a pupil at the Veterinary College, much merit, nevertheless, is due to him for his assiduity and attention to this disease, and for haring pointed it out as the general cause of this kind of lameness; for although it might have been previously known to exist in particular cases, it was not understood to be the general cause before Mr. Turner investigated the subject. 


\section{CHAP. VIII.}

\section{ON THE NERVE OPERATION.}

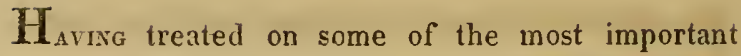
diseases of the feet of horses, which arise from the various modes of shoeing now in use, as well as from other causes, and having also pointed out the most reasonable means of averting those diseases, as well as for their relicf, I shall hereafter describe the different plans of shocing which have produced them. But as $I$ have, in the preceding part of this work, shown that there are numerous cases of lameness where no rational hope can be entertained of obtaining relief from any method of treatment hitherto known or adopted, in this or any other 
country, and a remedy having been discovered for the relief of cases of this kind, it may, I think, fairly be considered as an era in the Veterinary Art. In cases of lameness, hitherto considered as admitting of no relief, viz. all those permanent diseases of the feet, which have been so frequently adverted to, it has been proposed by Mr. Sewel of the V'eterinary College, to divide, or rather to amputate a part of the nerves which go to the foot. This operation is, on some occasions, performed below the fetlock joint on both sides, and on other occasions above the joint. The success, that has attended this novel and great discovery, most decidedly claims, not only the praise of every professional man, but of the public at large.

After a number of successful cases resulting from this operation, there were persons that attempted to take away the merit of the discovery from Mr. Sewel, by stating that Mr. Moorcroft had performed the operation twenty years ago. Admitting that as fact, what does it shew? That no beneficial result originated from Mr. Moorcroft's attempt; for if there had, we should have heard of it either from him or his successor. It therefore appears, that if $\mathrm{Mr}$. Sewel had not shown its utility, we should never 
have heard of Mr. Moorcroft having

I have also heard Professor Colemaı performed the operation more than $t i$ back; but when he said so, he by no means $\mathrm{i}_{\text {i. }}$ to lessen the credit due to Mr. Sewel; on the contrary, he imputed blame to himself for not persevering in it. I have heard there are other persons who have attempted to insinuate a sort of claim as being the suggestors of this operation. They are, however, in my opinion, all without any foundation in truth. I have considered it necessary to make these remarks to oppose any insidious attempts to rob Mr. Sewel of the fame he has so justly acquired. Some evils certainly attend the performance of this operation; but I look at them as I should on the explosion of a powder-mill, a steamengine, a gas apparatus, or any serious evil which may occasionally attend any useful and important invention; and however such accidents may be lamented, powder and gas will be made, and steam applied as a mechavical power.

The fair way of balancing the account is, to put the evils in one scale and the advantages in the other, when it will appear which preponderates; and as far as my observation goes, and from all the 
irfi rmation I have, it is greatly in favour of the litter. The evils I allude to are the loss of hoofs, consequently a loss of the animal. Two cases which occurred at the Royal stud may serve to illustrate others: a mare seven years lame, and another five, were operated on for experiment. They both became sound; but about nine months after the operation, there appeared in one case a trifling separation between the horny and sensible sole at the toe. This increased daily, notwithstanding all my endeavours to subdue inflammation; it then extended to the coronet, and at this time there was considerable inflammation and swelling of the leg: the separation increased round the coronet, and in a short time there was a separation between the horny and sensible laminæ. I should have rather said insensible laminæ, as there was not the least sensation in the foot at this time. In this state the coffin-bone was let through the hoof, and was fractured in many pieces. The other case was very similar to this, and I have heard of other cases, where the animals, as it were, walked or stepped out of their hoofs. The progress and result of these cases are very distressing; but on any future occasion, and where a similar fate appears inevitable, 
the slaughter-house is the only humane course for adoption. 1 have heard of many similar cases in different parts of the country; but, on the other hand, I see many fine and valuable horses at work, that were of no use to the owner before the operation, and have continued at severe work now two years without any return of lameness; and I see no reason why they may not be as effective as they now are many years to come. It therefore becomes a question with the owners of lame horses, where no other remedy offers to be of any advantage, whether they will work them lame, sell them for little or nothing, or risk the chances of the nerve operation. A determination of these alternatives will much depend on the kind of work a horse under these circumstances may be required to perform. If a lameness is not severe, a horse may do slow draught without having recourse to the operation; but, on the other hand, if a horse is required for quick draught or for riding, I conceive there are few persons that would not risk the chances of the operation. With stallions and brood-mares there can be no necessity to risk it, except in extreme cases of lameness. The two instances mentioned of failure in brood-mares that had been some years 
previously lame, but on becoming sound again never performed any sort of work, proves the experiment to have been made under every favourable circumstance : it however shows, that success much depends on the state of the feet previous to the operation.

In lameness of very long standing, where a change of structure has taken place to any considerable extent, and more particularly on the state of the joints within the foot, if the disease does not amount to a destruction of a joint, but a secretion of the synovia or joint oil has been stopped, and the cartilaginous covering of the ends of the bones are in a state of erosion, the animal is enabled, by the loss of sensation in the foot, to bear a greater degree of weight on these parts than they have been for a long time accustomed to; by which means are brought on all the distressing symptoms previously described. It therefore appears that the chance of success depends much on the length of time the disease may have existed previously to the operation. With horses with thin flat feet and weak laminæ, the operation is not so likely to succeed as with those where horn abounds. The structure of the horse's foot is particularly favourable to the success of this operation, as there are no muscles within the 
horny box; therefore as the powers which put the foot in motion are situated at a distance, a division of the nerve going to the foot bas no effect in paralyzing any parts which are necessary to its motion; which might have been the case had it been otherwise constructed. It has been imagined, that the foot, after this operation, would become a mere block, and that the animal would be rendered dangerous to ride or to drive. On making close observations on this point, I am glad to find that it exists only in the imagination, as horses that we have now at work, who have undergone the operation nearly two years, are considered quite as effective, in every respect, as those which have not required it. It has also been stated, that the hoof and foot waste after the operation; but $\mathbf{l}$ am glad to know that this observation is imagnary also. I have observed in hoofs where the operation has been performed, a more plentiful production of horn than before, and a greater disposition to grow in the natural form; and I think this is a consequence to be expected, as the irritable state of the foot being destroyed by the division of the nerve, the secretion is more likely to go on freely. When the operation has been performed before any considerable change of structure 
has taken place, I have no doubt that the original cause is in time removed altogether, by the animal being enabled to bear the full proportion of weight on the lame foot; as I have shown, that if the foot, from any cause, is long kept in a state of relaxation, the horn soon contracts, and tightens on the internal contents, and hence arises the utility of the patten shoe being applied on the sound foot in cases of lameness.

I consider the nerve operation an important discovery, and I luave no doubt that it will stand the test of ages. Some veterinarians exclaim against it, who nevertheless continually perform it, and assign as a reason, that they operate because it appears to be the only remaining resource; and that if they declined, others would not. Others condemn it as barbarous and cruel, and call it tearing out the nerve. I rather suspect that this disapprobation originates in the circumstance of the discovery not having been made by those who thus oppose it. Opinions of this kind from persons long in the profession may, perhaps, conceal the usefulness of this operation among their individual friends, but the important benefit it has already produced is, I trust, too great to be overlooked by the public. The term tearing 
is also inappropriate, as in the operation, which is momentary, the nerve is divided with a knife.

It is usefil to know that where the nervous influence has been restored, and lameness in some cases has returned, a repetition of the operation has been attended with the same advantiges as in the first instance.

The operation itself is very simple. Having first ascertained the course of the artery by the pulsation, an incision is made through the skin, about an inch and a half or two inches in length; and on removing the cellular substance, the artery, vein, and nerve are all shown running together, the nerve on the inside of the artery and close to it. A needle may be readily passed under it, leaving a thread, which, on pulling a little, enables the operator to separate the nerve from the artery with ease, and to take out as much as is considered necessary; after which, the skin should be closed with a stitch, which sometimes heals by the first intention; after which bleeding and physic are useful.

Since writing the preceding remarks on this useful operation, the subject of one of the cases I have alluded to as having worked sound nearly two years, has received a deep wound through the point of the frog, in that foot which liad been ope- 
rated on above the fetlock joint. Considerable inflammation came on, and the horse became very lame; however, through the means usually adopted to subdue inflammation, he became sound again in a few days. 'This at once establishes the fact of sensation being again restored; and 1 have no doubt that this is one of those cases where the original cause of lameness has been removed by the operation, and that now he is no longer liable to those disastrous consequences, which on some occasions attend the performance of this operation. When it is performed below the fetlock joint, there is less chance of the part operated on being struck by the opposite leg, and sensation is more likely to be restored sooner than when performed above, in consequence of there remaining a small branch of the nerve which goes undivided to the front of the foot; but in laying the nerve bare in this situation there is more to cut through, which produces great inflammation and much swelling, and is often long in healing; but if the operation is performed above the fetlock, the inflammation and swelling is trifling in comparison, when performed below the joint. I therefore, on the whole, prefer to operate above the joint. 


\section{CHAP. IX.}

\section{OF THE FRENCH SYSTEM.}

THE French shoe is perhaps rather wider than the common English shoe; it is convex on the ground side, and concave on the foot side, and equally thick throughout. It has eight nail holes at equal distances round the anterior part of the shoe; but the last hole on the inside quarter is generally at a greater distance from the end of the shoe than the one on the outer quarter; the holes are punched with a square countersunk head, deep into the shoe, and at some distance from the outer rim, and they are made obliquely, to give the point of the nail a direction outward. 
On the foot side of the shoe there is a much greater space between the nail-holes and the outer edge than in the English shoe; and instead of the sloe being straight from the toe to the heel, it is considerably curved at the toe, which is called by the French veterinarians "the adjusting balance."

It has been objected by some persons, that this shape is unuatural, because it does not correspond with the form of a foal's foot; but this opinion, I think, does not in any way prove it to be so, heca:sse the coronet at that age is considerably wider than the base of the foot; hence, if such a notion was correct, we might expect to see the base smaller than the coronet at five years old, when the foot is full grown.

The advantage of the French method of nailing on the shoes, is so very superior to the English, and the form of the shoe is so admirable, that I cannot conceive, situated as we are so near to that country, how so superior a system has not long before this period been attempted among us, for we certainly have not seen any plan of shoeing, which possesses so decided a superiority.

The advantage of the manner in which the French nail on the shoes will be noticed in the chapter upon 
nailing. I shall, therefore, here mention only the benefits of the shape of the shoe.

In the work of Monsieur Jauze lately published on shoeing, the advantages of the French form are pointed out, and contrasted with the English. His remarks upon the consequences likely to follow the use of the common English shoe are certainly substantiated by the deplorable state of our horses' feet.

If we refer to the action of the fore-leg, it will tend to explain some of the advantages of the curved shoe.

When a horse is about to move, the first indication of motion in the fore-leg is a bend at the knee, which necessarily raises the heels, and they become more and more elevated, till the toe (which is the last part that leaves the ground) is lifted for the moment that the foot is suspended. The base of the foot, just at its leaving the ground, is almost perpendicular when the knee is bent to its fullest extent; the foot is then in the same position with the heels of the shoe pointing upwards. If we consider this first part of the motion of the limb, we find the movement of the foot very nearly describes a semicircle; and on viewing the form of the joints connected with action, the necessity of a 
curve at the toe is clearly demonstrated: again, the form of a shoe worn out at once shows that it must be more suitable to put on a new one of that form, rather than suffer the action of the leg to be opposed until it is worn to that shape. In the second part of the action, when the foot comes again to the ground, the quarters and heels touch first, and they are the only parts occupied in placing it on the ground again. There may be deviations from this general rule, as in those horses that have bad action; also when horses are drawing heavy weights, it must necessarily differ. The fore-legs may be considered simply as pillars of support, having no power of themselves to propel the body forward, progression being entirely performed by the hind parts. If it were not so, the action would be different, as I have before observed it to be in those horses that have great weights to draw, and this may be more readily observed in any draught horse going up hill.

1 have offered these few remarks upon action, in order to bring the reader's attention to the curve of the French shoe at the toe. This form of shoe certainly harmonises more with the motion of the fore-foot than the English does; it affords a greater surface of bearing at the toe, than the projecting 
ridge of the straight ordinary shoe, and is much more calculated to allow of the motion of the leg and foot, the labour of the muscles is also diminished, and the limb being in its natural position, the ligaments have less imposed upon them; they are more at ease, and consequently are not so liable to be strained.

It may not be inapplicable to remark the facility with which the Indian people move in their wooden shoes, which are considerably curved at the toe, when compared to the difficulty of moving with those, that have a straight unyielding sole.

The shape of the coffin-bone (see plate I. fig. 2.) is also another proof of the French system being more consistent with the principles of nature, than the straight ordinary shoe.*

If we contrast the curved form of the French shoe, with the straight line of the English, it is very

* If the coffin-bone of a fore-foot is placed upon a level surface, the quarters and heels are the only parts in contact with it ; which proves that they are intended by nature to meet the ground first, and to bear the greater proportion of weight; but if the quarters of the hoof be removed to admit of the straight shoe, the portion of weight intended to be borne on the quarters must be thrown upon the heels, and hence the great mischief which ensues from the common English shoe. 
obvious, that the latter is as much calculated to oppose the action of the leg and foot, as the former is to facilitate it. For in order to apply the straight shoe, the toe is allowed to grow and to project far beyond the extent proper and necessary for the protection of the internal contents: and in addition to this, if the shoe be made three times thicker at the toe than at the heels, ${ }^{*}$ (he opposition to action must be increased in proportion.

Notwithstanding that I am fully convinced of the decided superiority of the French method of nailing on the shoes, and of the peculiar advantages of the curve at the toe, still I have two objections to the French system in general, viz. the convex form of the shoe on the ground side, and the concave form on the foot side. I object to the first because the horse is by no means so safe or secure on his feet, more particularly when going over stones. To the second, I refer for my objections to the chapter on the common English shoe, where the effects of the concave form of the foot side of the shoe are fully described.

* The shoe recommended by Professor Coleman is three cimes as thick, at the toe, as at the heels. - AM. ED. 


\section{CHAP. $\mathbf{X}$.}

MR. GOO DWIN'S SYSTEM.

$I_{N}$ the preceding pages the reader will have observed, that I have noticed many advantages in the French principle of shoeing, and that I have stated that it is, in my opinion, superior to any system that has come within my observation.

From the information I have been able to collect from Fiench authors, from veterinary surgeons, from cavalry officers, and other persons who have attended to the subject when in France, and who have particularly observed the state of the feet of horses in that country, I am fully borne out by their testimony, and my own experience. 
In a conversation with Mr. Sewel, the Assistant Professor at the Veterinary College, who has recently twice visited the Continent to enquire into the state of the veterinary art, he remarked, with a degree of earnestness that showed the impression which their mode of shoeing had made on his mind, "That he had seen more lame horses on his return, in the stage-coaches from Harwich to London, than he had met with during both his visits on the Continent." In the report which Mr. Sewel has lately published, addressed to the governors and subscribers to the veterinary college, it appears that he travelled through France, Germany, Prussia, Flanders, and Holland, visiting all the public veterinary schools.

Mr. Sewel was apprenticed very young at the Veterinary College, where he has continued to this time, and I think, after twenty years' experience in the principles of pressure on the frogs of horses' feet with thin-hecled shoes, that it must be admitted, that he is fully competent to appreciate the merits of such a doctrine.

After the foregoing declaration, 1 will leave the reader to draw his conclusions on Mr. Sewel's opinion of the thin heeled system, or of any other at present in general use in this country. 
To Sir Benjamin Bloomfield, who is on all occdsions ready to promote whatever appears likely to be useful, I beg perm.sion publicly to express my respectful gratitude, for having obtained for me so admirable an opportunity to ascertain the superior advantages of the French system, with such alterations as occurred to me, in the extensive royal establishment with which he is connected. It is very gratifying to me to find, after four years' trial, that the establishment is daily deriving benefit from its adoption; and I trust, that the public also will eventually be convinced of the many advantages which this system possesses.

In describing the French method, I observed that there were, in my opinion, two great objections to the shoe used in that country, viz. the convex ground surface, and the concave foot surface; my reasons for disagreeing with this form on each side of the shoe, have been stated in the chapter on the French system. In the shoe I have adopted, I have reversed the form on each side, making it concave on the ground-surface, and convex on the foot-surface, with an inclination from the inner to the outer rim. To effect this form on each side, it is necessary that the shoe should be sloped or bevilled on the ground. 
side, from the outward to the inward part all round the shoe, except about an inch and a half at the heels. To accomplish this inclination on the footside, it is necessary to thicken the inner part at the heels, as far as the flat surface extends.

It may be supposed, that a plane inclining the reverse of the common English shoe, will produce diseases in the feet of horses which have not appeared before. This is probable, if the inclination be carried to an extreme; but some years have elapsed without an instance of the kind in my practice. I consider, therefore, that it is not likely to occur. There is only one class of hoofs that such a shoe could be applied to, viz. those with extremely concare soles, which are invariably strong, and have abundance of horn, and require a greater opposition than any other to counteract contraction by the inclination of the plane. With all other kinds of feet, if the shoe is clear of the sole, it is not practicable to make the inclination to such a degree as to prove injurious.

The manner of punching the nail-holes, and the curve at the toe, are similar to the French; but it is necessary that the outward edge of the inside of every shoe should slope inward to avoid cutting. 
This comprises the form of the shoe I have adopted with so much success; and it is satisfactory to find, that the form of this shoe presents no difficulty to any moderate workman, and when a little accustomed to the shape, it is made with more ease than the common shoe. For general work, the best English iron will last until the hoof wants paring. From three weeks to a month is a right period for shoes to remain on the feet ;* but for hard-wearing horses, and those that work hard, English iron will require steeling at the toes; but in such cases Swedish aron will be the best. Having mentioned the peculıar advantages derived from the curve at the toe, I consider it necessary to make some remarks on the advantages of the form of each side of the shoe. The concave ground-surface renders the animal more secure on his legs, as he bas a greater purchase on the ground, and by this form the weight is thrown on the crust, or wall, which prevents any unnecessary strain on the nails and clinches.

* Mr. Goodwin in a postscript to his work, states the absolute necessity of taking off shoes as oftell as once in three or four weeks (whether they be worn out or not tor the purpose of removing all superfiuous horn, and to preserve the boof in its proper form and size,-AM. ED. 
In a work published nearly a century since by Soleseil a French veterinarian, he recommends an Inclined plain outward on the foot-side of the shoe, for contracted feet; but his method of obtaining this desirable form, is objectionable, inasmuch as he proposes to thicken the inner rim, and to slope or bevil the shoe gradually to the outer, leaving it much thinner than the inner one. No doubt a regular plane inclining outward may be obtained in this way, but it is at the expense of making the ground-surface very convex ; by which means all the points of bearing must necessarily be on the inner rim, when thickened and raised sufficiently to clear the sole. This form of shoe, though calculated to oppose the disease for which it was intended, produces an inconvenience which I have endeavoured to avoid, viz. an unnecessary strain on the nails and clinches, and all the consequences of their starting; it besides furnishes a very insecure form for the ground-surfice.

The plane inclining outward on the foot-side of the shoe, $\mathrm{I}$ am aware may by some persons be objected to as impracticable; but as I had formed an opinion, that a shoe so shaped might prevent contraction, and other permanent diseases of the feet, I determined to try it, because it appeared evident to 
me, that when the weight of the animal comes on shoe of this form, it must have a tendency to expand instead of to contract the hoof, and 1 have o und, from much experience, that the obstacles opposed to this form existed only in theory, as there are none in practice.

It is, however, necessary to remark, that the degree of inclination must be regulated by the previous state of the foot, and its propensity to contraction. There are, like all other general rules, exceptions to this ; but they are, however, very few. When it is recollected that the horny sole, if not diseased, is concave, it will in course admit of a convex surface being applied to it ; and when the superfluous parts of the horny sole produced since the last shoeing are removed, and the crust at the quarters are preserved firm and good, there is scarcely an instance where this mode of shoeing cannot be put into practice, and sufficient room be left also to pass a picker between the shoe and the sole to the nails. Should a foot, however, be in such a state as not to admit of a shoe of this description, if the horse is valuable, I have before recommended rest in a large loose place or paddock until the horn is restored; but if he is required to be shod under these circumstances, 
the state of the foot will in general indicate the form of shoe most suitable for the occasion.

Having described the shoe I prefer and recommend for general use, I must explain the necessary previous preparation of the foot in order to receive it. When hoofs are protected by shoes, the consumption of horn by wear and tear is nearly prevented; but as the growth of the hoof is constantly going on, it is evident that all the superfluous parts will require to be removed at every period of shoeing, otherwise it would run into a state of exuberance similar to the human nails, if they were not cut. The first part to be reduced is the toe, which should be removed with a knife or rasp on the soleside of the foot, keeping in view the necessary curve: the next parts are the heels, which should, if they descend below the frog, be rasped to bring them on a level with it: having attended to these two points, it will then be seen how much it is necessary to remove from the quarters, leaving them full and strong, but in a straight line from the heels to the curve, which allows the foot, when in action, a flat part to land on, and describes a space equal to the landing part of the foot when shod with a parallel shoe. This direction differs a little from the French 
"adjusting balance," inasmuch as they direct four points of adjustment at the toe, and two at the heels, which leaves the quarters rounded, and renders the foot not so secure on the ground. The sole next must have attention, the superfluous parts of which that have appeared since the last shoeing should be removed, this will leave it concave, and the crust or wall below the sole. Mr. Moorcroft observes, that paring the soles has a tendency to bring on pumiced feet, but I have not cbserved any such effect; on the contrary, if the sole is allowed to grow too thick, it looses its elastic property, and the sensible sole suffers in proportion to the degree of thickuess and want of elasticity. The next and last part which requires attention is the frog. If it is smooth, firm, and even on its surface, cleft, and sides, it will not require the use of the knife; but if it be too large, rough, or uneven in its appearance, all the superfuous parts should be removed in the way I have described in the chapter on thrushes. The foot will now be ready to receive the shoe, which may be applied without fear of produciug any inconvenience from the alteration which has been made from the previous method, but which, on many occasions, has been the cause of serious mischicf, in going from one plan to another. 
It is necessary to observe when a shoe is nailed on, that it should be about one-eighth of an inch wider than the hoof at the heels, also a trifle longer than the termination of the horn, or as much wider and longer as is necessary to prevent the shoe imbeding itself within the crust,* between the periods of shoeing. This would take place by the growing state of the hoof, if it were an exact fit when first put on, and often produce corns, \&c.; it is equally necessary, that the shoe should be neither too wide nor too long, as that would produce a leverage that would be injurious to the foot. It may be supposed; that, by leaving the shoe wider than the hoof, cutting would be a consequence, but as the heel is not a part where striking occurs, there is nothing to apprehend, as the cutting part of the foot is before the quarter; and approaching nearer to the toe. It is also neces-

* This direction is too apt to be neglected. When smiths are crowded with work, and have shoes ready made, it is for their interest to put them on, ' fit or no fit.' This is frequently done to the injury of the animal, and great inconvenience of the owner. When a shoe is too short or too narrow, in addition to the inconvenience of corns, \&c. above mentioned, it produces a strain upoir the foot ; as the weight of the animal is supported by a part, and not the whole crust.-AM. ED. 
sary to remove a small portion of the inner edge of the crust at the heels and quarters, leaving it sloping a little inward; this will fit it to the inclination of the shoe, and allow the crust a bearing on its whole thickness. With horses that have long pasterns, it is considered useful to increase the thickness of the shoe at the heels, with a view to give support and to counteract too great a bend in that part; nevertheless, if it is thickened more than usual, it is evident that it would occasion corns by increasing the pressure on the heels, and would also give them a shelving forward direction.

Having described the shoe, and the previous preparation of the foot to receive it, I consider it necessary to make some observations on the advantages that attend the adoption of it.

It has been shewn, in the preceding part of this work, that a material diminution of permanent diseases of the feet has taken place in this establishment, and also an evident improvement in them generally; and that the proportion of lame horses has been very considerably reduced. I could enumerate many instances where corns, contraction, and other deformities of the feet have been removed altogether. 
Notwithstanding the high opinion I entertain of the advantages of this method of shoeing borses over any other that has come within my observation, I am, however, prepared to expect that we shall occasionally have lame horses, not from causes occasioned by this mode of shoeing, but from the battering and concussion of the feet when in quick motion over stones or hard roads.

It has been imagined by some persons, that draft horses, when going up hill in curved shoes, cannot have the firm hold of the ground that the straight English shoe is supposed to afford, and that their fore-feet are more liable to slip back. Now 1 am convinced, that every one who has noticed the points of wear in the English shoe, will admit, that when the sharp edge of the toe of the common shoe is worn off, which is done in a very few days, the then form renders it far more likely to slip, than the broad surface of the curved toe, which, being at first put on of the shape which the English shoe acquires by wear, is consequently free from the disadvantage of the sudden and smooth slope thereby occasioned. Thus the supposed benefit of the straight shoe is of so short duration, as to be by no means an equivalent for the great inconvenience produced by 
it three-fourths of the time it is in wear, besides also the impediments which an elongated toe opposes to action.

Those persons who may be averse to the adjusting curve of the French shoe, will find that the next best shape is a perfect plane on the foot-side and the same on the ground side, of the width of the nail holes all round, (which should be of the French form, and the remaining part of the web or width of the shoe should be sloped or bevelled from the inside of the nail heads, all round the shoe to the inner rim, with the exception of from one to one inch and a half of flat bearing on the heels, and the shoe should be of an equal thickness from toe to heel. 


\section{CHA P. XI.}

\section{ON BAR SHOE S.}

[PLATE III. FIG. 3, AND 4.]

$\mathbf{P}_{\text {ERhaps }}$ there is no shoe which can be so generally applied as the bar shoe, and if I were compelled to confine myself to the choice of one, I should most decidedly select the bar; there is, however, a strong prejudice against their use, and I have, on many occasions, observed horses crippled, and very tender with plain shoes on, and compelled to work in that way rather than have a bar, when, in all probability, a bar might have enabled the horse to go sound. This prejudice has arisen from their not having been resorted to except in cases of emergency; so that, to see a horse with a bar shoe is considered as 
2 notification of some imperfection, which materially deteriorates his value, and as horses are for the most part a marketable article, it is not a matter of surprise why this circumstance should operate in this way; however, those persons, who may have a valuable animal possessing every desirable qualification, can have no reason to get a fresh rather than a good horse, when such a prejudice of fashion will have no influence. Bar shoes are intended to remove pressure from one part of the hoof and to convey it to others, and are used more particularly for corns, sand-cracks, pumiced feet, breaches in the crust, \&c. \&c. The manner of applying the ordinary bar is, however, very objectionable, as it corresponds in every particular with the form of the common shoe, with the exception of being continued all round, and uniting both hecls of the shoe together, forming a bar which covers the posterior parts of the foot. This bar is much narrower than the other parts, and is bevelled and thicker behind, and sloping towards the point of the frog. It is, therefore, similar to a hollow cone, allowing the weight of the animal to bear on an edge only, which produces all the injurious consequences of the common shoe. Pieces of sole-leather are frequently riveted on the 
bar to raise the shoe further from the part suffering; but in many cases where I have seen this practice resorted to, the increased pressure upon the frog produced more mischief than the disease it was intended to relieve; in other cases, some parts of the bar are what smiths call set down, so as to form considerable shoulders on the foot side, which are intended to take the bearing on the nearest sound part, leaving a hollow space opposed to the diseased part. This, however, can only be temporary, as the additional pressure thrown on the shouldered part is so great, that the strongest crust is not equal to it long.

A narrow bar in the centre of the shoe is on some occasions applied in flinty countries as a defence to the sole, and is said to be useful. I consider the great use of a bar shoe to consist in affording a greater surface of defence than any other shoe, which enables us to determine the weight of the animal more generally on the foot by equalizing the pressure on more bearing points than a plain shoe. There is a numerous class of horses whose hoofs are thin and weak, and not sufficiently strong to support the weight of the animal in battering over hard roads at a fast pace without inconvenience. This 
appears at the heels and quar ers, where, instead of the horn having grown much sance the last time of shoeing, it will be found to wear faster than it grows; that the sole is separating from the crust, which bends inwards, or projects in a shell outwards, and that the heels take a shelving direction forwards.

In all feet of this description these consequences shew themselves more or less, and for them I prefer a bar instead of a plain shoe, to prevent the destructive effects which arise from the use of any plain shoe.

I never find any difficulty in keeping flat-feeted horses sound, at work, with bar shoes; but 1 have frequently found, on a trial of plain shoes, that I was compelled to go back to bars again.

Instead of raising the bar by rivetting pieces of leather on it, or of forming shoulders or projecting parts the practice with the common bar shoe,) I propose it to take as much general bearing as the foot will admit, allowing the crust and frog to have an equal bearing to relieve the suffering part; it will only be necessary to remove the horn of that and the contiguous part, leaving a small space between the shoe and the crust. When the heels and quarters have been worn away, and the frog pro- 
jects below them, it will be necessary to set down the part of the shoe opposed to each heel, so as to admit a slight bearing on the frog, otherwise the pressure would be too severe; but if the heels and quarters are on a level with the frog, that precaution will not be required; a plain flat bar will in this case, be more suitable, and instead of making a narrow bar, which soon imbeds itself in the frog, and produces so much partial pressure that it cannot be worn long without inconvenience, I use a bar wider than any part of the shoe; of an equal thickness in all its parts, and perfectly flat on both sides, which affords a much larger and more even surface to tread on, and gives likewise more points of bearing on the frog. In every other respect a bar shoe corresponds both in form and principle with the plain shoe. 


\title{
CHAP. XII.
}

\section{ON THE PATTEN SHOE.}

\author{
[PLATE III. FIG. 1.]
}

$\mathbf{T}_{\mathrm{HE}}$ use of a Patten shoe is to raise one foot higher than the other when standing in the stable.

In cases of lameness, for any considerable time, either of the legs or feet, where probably the primary cause may have been removed, there is a want of action in the parts from a long previous state of relaxation; a shoe of this description is on such occasions found useful. To bring these parts into action this shoe is put on the sound foot, which raises the limb altogether, and so alters the position of the leg, that the horse can bear but little weight on that foot, and is therefore compelled to bear more weight on the lame leg. 
It is necessary to begin with this shoe for a short time, and to increase the use of it by degrees until it can be worn twelve out of twenty-four hours daily. Many clumsy and awkward contrivances are in use for this purpose, most of which are of a piece with the shoe; therefore, when it is put on, it must remain continually until the shoe is taken off again. The evil attending this is, that, on some occasions, the increase of pressure, which is continued constantly, is too great for the suffering limb to bear, and instead of being beneficial, when the shoe is taken off, the lameness is considerably increased. A great advantage is therefore obtained by making the patten moveable, which is effected in a simple way, and may be applied to any shoe which has been put on for ordinary wear. The only alteration consists in having a screw hole made on the outside heel, the patten being made of a requisite height from two to four inches from the shoe, with three branches or legs forming an arch from each heel of the shoe; the inside branch fixed on the inner rim of the shoe by a claw; the front or middle brancl advanced towards the toe of the shoe, where it fixes also by a claw; and, in the outside branch, a round hole opposite to the hole in the shoe, to which it is fastened by a screw. 
The direction of the middle branch, where it is connected with the arch of the patten, should be attended to, as otherwise it may lock in the gratings of cesspools; the branch from the centre of the arch should be perpendicular for an inch or two to prevent effectually an accident of that kind. In some cases of lameness, from an injury or inflammation of the joints, it may be useful to raise the heels of the foot to relax the limb during the state of inflammation. In these cases, turning up the heels of the shoe will answer the purpose. There are likewise other cases where the joints become diseased from the heels being elevated too much, and the weight borne on the toes; here it is necessary to elongate the toe of the shoe agreeably to the necessity of the case, observing that the elongated part is curved, otherwise it would do more harm than good. 


\title{
CHAP. XIII.
}

\section{ON S C REW SHOES.}

\author{
[PLATE III. FIG. 2.]
}

$I_{N}$ cases of contraction it has been considered by some persons, that mechanical power presents a simple and easy mode of relief; but the advocates for such a remedy should have well considered the probable consequences of a screw applied to a part though not in itself sensible, yet firmly united with living and sensible parts; and that any immediate alteration in form, produced by the screw, must equally affect the sensible parts which are united to it. In this way I have seen serious injury produced. Though screw shoes are an old invention, they were revived a few years back by a Mr. Jekyl. If 
the screw is judiciously applied, it is in some case attended with advantage; it should never be attempted with thin or flat feet, as it invariably produces mischief in them; but where there is plenty of horn, strong and firm, it may be used with a better chance of success. During the progress of the attempt, a horse must be put out of work, his shoes taken off, and his feet well saturated with water some days previously to the application of the screw. Various contrivances of this kind have been recommended by different authors, most of which are ill calculated to answer the intended purpose. All, that have come within my observation, have a joint at the toe, with a screw at the heels, the head of which projects from the outside heel of the shoe; by this means the shoe is in continual danger of being torn off by hitching on something, or being entangled in the litter. The shoe which Mr. Jekyl adopted was of this description, with as many nail holes as could be punched. A screw thick enough to an-wer this purpose without bending necessarily increased the thickness of the shoe to an unusual degree, and where one heel is more contracted than the other this shoe offers no means of applying the screw to either; and it is evident that the whole expanding 
power with this shoe is determined on the nails and clinches, which, on many occasions, tear out the piece before the object is obtained.

A shoe was suggested to me by Sir B. Bloomfield which obviates all these objections. It has two joints, one on each side of the toe, and is therefore made in three parts; a centre or toe-piece, which has two nail holes in it, and from the centre of this a branch or flat piece of iron about an inch and a half in width (of the same thickness as the shoe,) which extends over the centre of the foot to the termination of the frog, on which it is intended to bear. As this branch approaches the wide part of the frog it increases in width and thickness in order to receive a circular hole through it, which is made into a female screw on each side. The sides of the shoe have three nail holes in each, with a claw on the inner corner of each heel turned upwards, which are fixed on the back part of the refiection of the crust or wall, and may be called the beginning of the bars. The two joints being completed, the shoe is put on, and as the middle division of the shoe is kept on by two nails at the toe, it affords a fixed point for the action either of the inside or outside quarter of the shoe, or both, as may be required. 
Two short screws are necessary, which are applied in the female screws of the centre branch, and the opposite end of each acts in a small grove on the inside of the shoe at each heel. In a shoe of this description there are no projecting parts beyond the rim of the shoe, which is of the usual thickness, and having claws at the heels there can be no strain on the nails and clinches, and consequently no injury can be done to the crust during the application of it.

It is necessary that the hoof should be kept in a state of continual moisture; each screw to have half a turn daily, or every other day, as the nature of the case may require. Bleeding and physic are useful during this process, and a diluting diet, as it is not prudent to give exercise under this operation. From two to four weeks will be sufficient to obtain all the benefit that this shoe affords. The expansion takes place principally in the centre or cleft of the frog; if it were at the heels or the quarters, in the same degree as in the cleft of the frog, more mischief would arise by separating the horny from the sensible laminæ than any advantage that could be gained by the use of the screw. On the first appearance of expansion in the frog, however liseased (with ordinary cleanliness, and the application of a few simple 
remedies recommended for the cure of thrushes), new horn soon fills up the diseased cleft, and in a short time presents a frog full of sound and strong horn. If the screws are not turned gradually, or if they are applied too long, it will produce great mischief. When the screws are taken off a shoe similar to that 1 have recommended for general use, will prevent the heels from contracting again, which would soon take place with the use of the common English shoe. Exercise should at first commence with walking, and increase by degrees. In cases where I have not had success in the use of the screw for the relief of contraction, I have noticed a deviation in the growth of the hoof at the coronet itself; and, as it descends, it wrinkles, and grooves appear ; where they take place to any considerable degree, $I$ have never seen any good obtained by the use of the screw. On the other hand, I have on many occasions seen benefit from a judicious application of it. 


\section{CHAP. XIV.}

\section{ON F ULLERING.}

Shoeing smiths apply this term to the groove in the outer edge of the ground-side of the shoe, which is generally continued all round as near to the outer rim as the iron will admit; but in some instances it is made deeper, and is not carried round the toe. In the bottom of this groove the nail-holes are punched.

The object of this groove is to receive the nailheads, but in general it is too superficial to answer this purpose; when a countersink head is used, the groove is made deeper; but the inner edge of the groove is perpendicular, and the outer edge slopes towards the exterior rim, to give the point of the 
nail a slanting direction inward. It is considered, that the smith who can keep this groove nearest to the edge of the shoe is the best workman, and it is by them denominated fine fullering.

If this groove is cut deep into the shoe, it is evident that it must weaken it, and if the iron is not good, it will crack in the outer edge of the fuller, and if it is superficial it affords no security to the head of the nail, and if made with accuracy, and deep enough to afford security to the head of the nail, it is a tedious process, and takes up much time. The fuller, or groove, has been recently altered at the Veterinary College; it is now carried further into the shoe, and is similar to the German method of making the groove, which gives an advantage in taking more hold, by driving the nail through a portion of the sole on the inside of the crust similar to the French method of nailing.

Some persons have fancied, that by making two or three grooves round the shoe, slipping would be prevented; it does not, however, appear to be well founded, as such a practice is rarely seen. 


\title{
CHAP. XV.
}

\author{
O N P U N C H I N F.
}

THE ordinary English punch is square, and slightly tapering, and is made more for the purpose of gettıng it readily out of the shoe when the blow is given, than for the security that the form of the hole may give to the nail. It is applied in the centre of the fuller upon the depth of which the punched part depends. The nail-hole is as wide, or nearly so, on the foot side of the shoe, as it is on the groundside; the smith who brings the nail-hole on the foot side of the shoe nearest to the exterior edge is considered the best workman.

It must be obvious that a hole of this form affords little security to the nail. Burs are not unfrequently 
left on the foot side of the shoe, from the smith having omitted to remove or flatten them after punching; which sometimes produces mischief.

The holes of the Persian, Turkish, and Barbary shoes are punched round, but not near the edge, as they have no fuller. The German, Dutch, and Russian slioes are punched in the bottom of a coarse fuller. In the Portugueze method, the hole is very large, oblong, and square, extending far into the shoe, and is peculiar to themselves, and without a fuller. In the Spanish, Flemish, Italian, and Swiss modes, the punch hole is similar to the French.

The French hole I consider to be much the best, and it, in my opinion, possesses some important properties, but it requires two punches to form it perfectly; the first a small common counter-sink punch, which is struck nearly through the shoe, leaving only what is necessary to be opened by the pritchel; every hole having been opened in this way, a large and deep counter-sink punch is then used to every hole, which must be struck nearly as deep into the shoe as the first punch, to admit the counter-sink part of the head of the nail to be buried in the shoe. 
Much depends on this last punch being driven deep enough; if it is not so, a shoulder will be formed in the hole by the first punch being much smaller than the second; in this case the nail-head, instead of being sunk deep into the shoe, will stand out; consequently it will not have sulficient security, and the shoe will be more liable to come off.

Perhaps there may be a little advantage in sloping the inner square of the hole rather more than is done in the French method, to obtain a greater degree of obliquity to the point of the nail. 'The bottom of the hole is pritchelled in the usual way, only with this difference, that it is made to receive a flat instead of a square shank, and to be as near the size of the shank intended to be driven as pos-. sible, that the nail may fit and hare a direction outwards. Instead of following the French in thcir number of holes, which is eight, $I$ use seven, four on the outside, and three on the inside; this leaves the last bole of the inside at a greater distance from the beel than the outside, where they are carried much nearer to the end ; and instead of carrying the nails all round the front of the foot, I prefer leaving a solid space at the principal point of wear at the toe. 
On looking at the foot side of the shoe, the nailholes (unlike the English, which are very near the outer edge) extend a considerable distance into the interior part of the shoe, the use of which will be explained in the chapter on nailing.

If the quality of the iron is not good, it will be put to the test by the application of the punch; it will either burst on the outer part of the hole, or cracks or flaws will be seen; neither of which will appear if the iron be good. 


\section{CHAP. XVI.}

\section{ON FROSTING.}

$\mathrm{F}_{\text {rosting, like shoeing, is a necessary evil, but the }}$ inconveniences attending it show themselves much sooner than the effects of ordinary shoeing.

In order to avoid wounds by treading one foot on the other, it is the practice to turn up the outside heel only: it is thus so much raised, that it turns the foot on one side, and brings on an unusual strain on the ligaments of the joints, which often produces lameness. The toes of saddle horses are seldom frosted, therefore an unusual elevation of the heel, either by one or two frost ruffs, alters the tread so much, that it increases the action of some, 
and diminishes the action of other muscles accustomed to strong exertion; it is also manifest that a considerable increase of pressure on the heels would follow, so that lameness frequently attends the practice of frosting, even for a short time. The ordinary method of frosting, is by taking a shoe off, heating the heels or toes, and turning them up ruff; but this being iron only will last, for any efficient purpose, but a short time; and the same process must be repeated, perhaps daily, as long as the frost lasts. It is evident the hoof must suffer most severely by such a continued and repeated perforation with the nails, so that if a frost should last a month or two, it is probable there would be scarcely horn enough left to nail a shoe on with safety.

When frosting is required, I have found by steeling the heels, and if a draft horse the toes also, that they will last considerably longer, and consequently diminish the frequency of driving nails. A much shorter ruff also will answer, and the usual tread will not be so much altered. A ruff on the outside heel is sufficient, if on feet where horn abounds, and the horn of the same heel may be removed or lowered with safety, to counteract, in some degree, the depth of the ruff; but as with thin 
feet, and weak low heels, it is not practicable to remove horn, a bar shoe, with a ruff on the centre of the bar, is desirable, or a short ruff on both heels, observing to round the corners of the inside ruff, to obviate the effects of treading one foot on the other. Frost nails are frequently used, but the time they last is so short, that the practice is injurious; but if they are on an emergency resorted to, the head of the French nail presents a considerable substance for that purpose, but the common English nail very little,

Many persons have suggested to screw in the ruffs. I have tried screws in all feasible forms for this object, but I have never found that any screw would remain firm enough to answer any good purpose. The most efficacious method of applying a removeable ruff is to make a short square turn-up at both heels of the iron only, through which punch a square hole to receive the shank of a steel ruff, which is rivetted at the end of the heels, leaving the steel ruff in the inside of the iron ruff, about half an inch higher than the iron ruff. A steel ruff may be rivetted at the toe when required, in the same way, observing to rivet the shank on the outside of the shoe. To take these out, a few 
strokes of the rasp will remove the bur of the rivet, and by a trifling blow with a shoeing hammer it will come out. The steel ruffs should have iron shanks, and are easily made in a tool for that purpose. The use of removable ruffs for ordinary purposes, perhaps, may be considered tedious and too expensive, but in a country like Russia, where the frost continues regularly for many months, a previous preparation for the winter, would, I consider, be attended with great advantage. The application of ruffs for any considerable time produces corns, and alters the natural form of the heels of the hoof, especially if they are thin or flat, by inclining them to an oblique shelving direction forward. 


\title{
CIAP. XVII.
}

\author{
O F N A I LS.
}

'T' HE inconvenience and danger occasioned by casting shoes are too familiar to every horseman to require any comment. Sometimes a shoe may be pulled off by accident, but the causes may be principally attributed to the rottenness, together with the bad form of the nail. The first consideration should be the quality of the iron; if it be too brittle, which may be ascertained by bending a nuil once or twice, the nails soon break: in endeavouring to point them as it is termed by the smiths, the fibres split, the nail appears somewhat hollow, and is of no use; the number of nails wasted in ordinary 
shoeing forges, on an average, amounis to one-tliird. If we consider this as general before shoeing, it cannot excite much surprize that the shoes are continually coming off. This inconvenience might be very easily avoided by smiths, if they chose to have it otherwise.

The form of the ordinary English nail is ill adapted to answer the intended purpose, as it has a small head with an abrupt shoulder, a square thick shank three-fourths of its length, and the remainder flat, thin, and often too weak, eren to bear driving through the horn; the head usually stands out of the shoe; as the groove or fuller in the shoe, in which the nail-holes are punched, is so superficial as not to admit the head to sink into it, the nall-head therefore soon wears or breaks off, and as the shoe has but little purchase on the remaining shank, from the nature of the hole, the shoe soon comes off. The square thick form of the shank also ill agrees with the intended purpose; as it is the practice in all English shoes to drive the nails into the crust only, which in about oue-half the horses is very thin. This form of the shank is calculated to produce compression on the sensible parts, but to nbviate this, smiths, when pointing their nals, ham. 
mer the square part of the shank on the nail stake until it becomes flat and sufficiently thin to admit of its being $d r^{*}$ en with safety; but this endeavour to remedy the improper form of the nail produces another inconvenience, which facilitates the loss of shoes. Those, who are acquainted with the nature of metals, know that the hammering required to flatien the square shank compresses the fibres of the metal so closely together, and stiffens it so much, that it brings it to a state approaching to hardened steel; a slight blow or the ordinary concussion of action is suflicient to cast the shoe, when the nails, being all broken off just below their heads, leave the shanks in the hoof; and when the flat part of the shank is too thin in proportion to the thickness of the other part, all the endeavours of the smith to bring this thin part of the nail into a proper form, or stiff enough to drive, is unavailing, and hence arises not only great mischief to the foot, but also a great waste of nails.

A nail with a counter-sink head has been recommended, and as far as the head is the object, it is better than the common one; but to the remainder of the nail, in all that I have seen, there is the same objection as to the common nail. 
The French nail has a large square counter-sink head, (see Plate $\mathrm{IV}$. fig. 3.) which is received into a corresponding hole in the shoe, iuto which it sinks more than three-fourths of its thickness; a part of the head remains below the level of the shoe, and is flattened on four sides, leaving the centre of the hearl convex and pounting. The shank is flat, broad, and regularly taperiug to its point; in short, it is similar to the tire n:tl, with the exception of a flat instead of a square shink. The nails should be of different sizes, :rrreeable to the size and state of the foot.

I now offer some rcmarks on their comparative merits; between the English and the French nails. The latter I consuder to possess fal superior properties over any other. The large, deep, counter-sink head, as long as the shank remains sound, affords a security to the shoe while a bit of iron is left on the foot; but when the English head is worn off, which soon takes place, the shoe is no longer safe. Another security afforded by the French head is, that it is firmly supported by the four sides of the counter-sink hole; the English, by two sides only, and very superficially. The shank of the French nail being broad, fiat, and taper, does not require the hammering before spoken of as so lrejudicial; it therefore can be driven into the hoof with all 
the natural and genuine properties of the iron, requiriug only to be straightened, and stiffened a little at the point; but none of this stiffened part remains in the foot when shod, as that is twisted off by the pincers, and clenched on its appearance through the hoof.

As the head of the French nails take a little more time and iron, it is reasonable to allow that the manufacturer should charge more for them; but when the-trifling waste is considered, there will be very little difference of expense between them and the common nails.

In the choice of iron for this purpose, I beliere the Russiza which is brought from Archangel is the best, and it should possess the properties of malleability and tougbness: a good nail of a fair quality will bend backwards and forwards from eight to twelre times or more, before any evident marks of breaking appear on the bent part; if the iron be not good, it will crack and break at three or four turns, and split in pointing. Swede iron, from the superior strength and body of metal, seems to offer great advantages; but smiths in general prefer the best Russian, because they think that the former, though sound and strong, is too stiff for the manufacture of horse nails. 


\title{
CHAP. XVIII.
}

\author{
O N N A I L I N G.
}

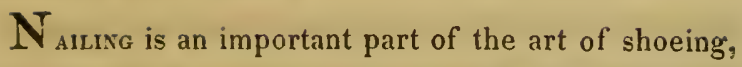
and deserves mature consideration, as upon it very much depends whether a horse goes sound immediately from the hands of the smith. From a defect in its principle, nailing contributes to the production of those permanent diseases so frequently spoken of. If lameness is caused by a direct stab, it will be seen instantly, as it arises from taking too much hold, pitching the nail inward, and at the same time driving too high in the crust; or from the point of the nail splitting, and taking a contrary direction to what was intended. 
In other cases where the injury is not severe, and where the nails are driven too near, and press on the sensible parts, lameness will not show itself so soon; and the time of its appearance after shoeing will be in proportion to the degree of pressure. In all cases of lameness, where there is no particular external indication, it is prudent to take the shoe off, when, if it proceeds from the effects of a nail, it will soon be discovered; the usual remedies to counteract inflammation will succeed in these cases. Collections of matter on some occasions are found, and produce troublesome ulcers, difficult to heal; they are, however, only of a temporary nature. It must have been observed, from the ordinary fuller being made too near the outer edge of the shoe, and from the manner of punching the holes in the fuller, that the nails are intended to be driven into the crust, and Mr. Coleman observes, that, so long as nails are made of iron this must be the practice; nevertheless, it is not so at the College now. It has, however, been productive of great mischief, inasmuch as it has a tendency to break down and destroy that defence which nature intended to protect the internal sensible contents of the hoof. 
When the diameter of the crust is considered, even in perfect hools, and compared with the diameter of the shank of the ordinary nail, it cannot excite surprise to see the hoofs of horses split and mutilated in the manner they are; but when it is considered that one-half of the feet of horses are defective in the natural production of horn, and have consequently a thin crust, this mode of nailing must add considerably to the number; and as it has been shown by the nature and direction of the hole, that nails must be pitched inward, and as the hole is so near the outer edge of the shoe, the nail must necessarily be driven a considerable height in the crust, to get hold enough to afford the shoe the necessary support; and the nail having been driven inwards, it must, in the course of its direction through the hoof, before the point comes through, have taken a curved direction, when the curved part being the nearest to the sensible contents, it must more or less have a tendency to press, in proportion to the degree of curve and approximation, on the sensible parts.

Much depends on the proper size of the nail. I have on many occasions seen smiths, for want of a proper assortment, drive large clumsy nails into 
small delicate feet, and on the other hand, small feeble nails, not large enough to fill the clumsy holes of a heavy shoe, for a large foot. The nailholes are generally too near each other; so that the frequency of driving nails so near together, renders that part of the crust a mere shell, full of holes: and the difficulty is great, which smiths frequently meet in finding even a sound piece of horn to drive the clinch through. It is not unfrequent to observe a smith drive a nail half or threefourths of the way, then pull it out again, get a fresh nail, give the point a new direction in search of a bit of sound horn to drive some part of the nail in, and repeat this driving and pulling out again eight, ten, or even twelve times, before he considers the nail safe ; and it is by no means an uncommon occurrence when shoes are taken off, to find where the nails have perforated the crust in the way described, the whole piece come off with the shoe as high up as the clinches. The consequence of such a breach in the wall may be readily imagined, the smith is obliged to look to the remaining part of the crust, where it has not been usual to drive nails, to keep the shoe on by any means, he is therefore driven to the toe and heels, or indeed any part of the wall, 
where he thinks he can get a nail in, and when the manner in which the weight of the horse is bearing (only on an extreme edge of the shoe) is considered, there must be an unnecessary strain on the nails and clinches, and consequences, like those mentioned, are unaroidable. As I have already stated that a breach in the wall on one side the hoof is frequent, and as it sometimes happens that both sides of the foot are torn off in this way, the toe and back part of the heels are then the only remaining parts where a nail can be driven, and the weight of the animal is thrown on these two points; it may thence be readily imagined that he will not work long in this state; a run at grass for several months will be necessary to restore this loss and waste of horn. It is, however, probable, that so much mischief has been done to the foot, that a run at grass will not remove the consequences, and that some permanent disease has taken place.

In the ordinary manner of nailing, we either see the nail-heads standing far out of the shoe, or the head is so small, or has been so rasped by the smith to bring it more on a level with the shoe, that a few days will wear it off. Grooms and coachmen have a practice of taking their horses to the forge be$9 *$ 
tween the periods of shoeing, or to require a smith to attend every Sunday morning to knock down and tighten all the clinches, and to renew nails. The starting of the clinches arises from the shoe getting closer to the foot after it has been on a short time; and as the bearing is only on the outer edge, it imbeds itself in some degree within the crust; thus the distance between the nail-hole on the foot side of the shoe and the clinch must be shortened, so as the shoe gets closer to the foot, the clinches are pushed further through the hoof, which produces the starting of the clinches, which invariably attends the English manner of shoeing.

It sometimes happens that a clinch is not pushed further through the hoof, but has started on the ground-side between the head and the shoe, whence it becomes loose and no longer performs its part in retaining the shoe on the foot. It is obvious that any plan of shoeing, which produces a starting of the clinches, must render the shoe very insecure on the foot; for the moment the clinches begin to start, the only remaining support is afforded by the shank alone; and should the shank have been driven through horn already split and shelly, it will account for the number of cast shoes which are perpetually 
seen. It is too much a practice with smiths to make a nick in the hoof with an edge of the rasp, under every nail, previous to turning the clinch; this is done to let the clinch within the hoof, and to give it a finish: but it is a bad practice, as it much weakens the hoof. It may be necessary to remove any rough part which the nail may have forced through the horn, but to give the foot a finish the rasp is too liberally applied to the clinch itself, to weaken it until it is on a level with the hoof; the part of the hoof between the shoe and the clinches never fails to receive this finishing stroke, which is very injurious, as it diminishes the thickness of the crust. It may also be necessary to round the bottom edge of the crust to the shoe, but that is all which is required.

Having described the imperfections of all the plans of nailing that have come within my observation in this country, I shall now explain a practice which appears to me to obviate those inconveniences. The French"method has some properties admirably calculated to answer a better purpose, for instead of driving the nails into the crust, a greater hold is taken, as the manner of punching the hole indicates; the nail is driven within the crust, consequently 
going through a portion of the sole, it takes a short oblique outivard direction through the crust, which is the reverse of the Euglish plan, as has been shown: their nails have an inward direction. By taking so much hold, and giving an oblique outward direction, the smith is enabled to bring the clinches much lower in the hoof, and nearer to the shoe: this direction of the nail affords a much stronger hold of the foot, and is less liable to split the crust.

An English smith, on a first view of the distance that the French punch their nail-holes from the outer edge into the shoe, decides, that they cannot be nailed on the foot with safety; a little practice, however, proves that it is not only a safer, but a far more secure method. What is here said has a reference only to taking more hold, and directing the nail obliquely outward.

I have already mentioned, that I consider the foot side of the French shoe objectionable, as far as relates to its concave form, which must produce an unnecessary strain on the nails and clincles by resting on the outward edge of the shoe, causing the clinches to start, and to produce all the bad effects occasioned by their starting. 
The shoe which I have adopted obviates these inconveniences, and I cannot adduce a proof more convincing of the truth of this than that on an inspection of the feet, when horses are brought into the forge to be shod afresh, I have generally found the clinches firm in the hoof and without any appearance of starting, which 1 consider to arise from the plane of the shoe inclining outwards, and embracing the crust so firmly at first, that it does not admit of any alteration in the distance between the shoe and the clinch during the time of wear.

It therefore appears that the following important advantages arise from the French method of nailing, viz. preservation of the wall or crust, and a more secure retention of the shoe on the hoof, and when combined with the alteration in the form of the shoe, which I have adopted, it is calculated to prevent contraction, and compression of the sensible parts within the hoof.

The facility with which smiths nail on these shoes when fitted, is not one of the least advantages of this system. All the sniths that I lave met with state, that after a little practice they can nail on three of these shoes with more ease, and in less time, than two of any other form, and it is a rare 
occurrence to see a nail wasted. Indeed the preservation of the crust by the short and oblique hold, and the security with which shoes are kept on, at once indicate all these advantages, and also that at every period of shoeing the hoofs have grown sufficiently to afford sound horn to drive the nails through, as well as the great security that the large and deep counter-sink head forms with the shoe. 


\section{CHAP. XIX.}

\section{OBSERVATIONS ON BLOOD-LETTING.}

[From J. Clark's Treatise on the prevention of Diseases incidental to Horses.]

A Lthougla the method of performing the operation of blood-letting is generally thought to be pretty well known, yet there are many untoward accidents that frequently happen from the unskilful and inexperienced, in performing this operation.

$\Lambda$ s horses are naturally timorous and fearful, which is too frequently increased by bad usage, and improper chastisement, they require, in some cases, particularly in this of bleeding, to be taken unawares. or by surprise, and the orifice male into the rein before their fears are alarmed; for this rea- 
son the fleam and blood-stick (as it is called) have been long in use, and, in skilful hands, are not improper instruments for the purpose; although, with many practitioners, the spring-tleam would be much safer, and, on that account, ought to be preferred. When a lancet is used, the instant the horse feels the point of it, he raises or shakes his head and neck, in order to shun the instrument, before the operator has time to make a proper orifice, which frequently proves too small or too large; for this reason, those who have tried the lancet have been obliged tn lay it aside.

Many people tie a ligature or bandage round the neck, in order to raise the vein, and that they may strike the fleam into it with the greater certainty; but a slight view of its effects in preventing this, and its other consequences, will show the impropriety of this practice.

When a ligature is tied round the neck, previous to bleeding in the jugular veins, it is to be observed, that it stops the circulation in both veins at the same time; hence they become turgid and very full of blood, insornuch, that they feel under the finger like a tight cord, and, as the parts around them are loose and soft, when the stroke is given to the fleam, the 
rein, by its hardness or tightness, slips to one side; of course it eludes the stroke; hence a deep wound is made by the fleam to no purpose, and this is sometimes too frequently repeated. Unskilful people have likewise a custom of waving or shaking the blood-stick, before they strike the fleam, in view of the horse, whose eye is fixed on that instrument, and, when they intend to give the stroke, they make a greater exertion; hence the horse, being alarmed by its motion, raises his head and neck, a disappointment follows. The struggle that ensues, by this means, prolongs the operation; the ligature, at the same time, being still continued round the neck, a total stagnation of the blood in the vessels of the head takes place; and hence it frequently happens, that the horse falls down in an apoplectic fit. In such cases, I have observed the operator greatly disconcerted, and desist from any farther attempts to draw blood at that time, being prepossessed with the idea that the horse was vicious and unruly, although the very treatment the horse had just undergone rendered bleeding at this time the more necessary, in order to make a speedy revulsion from the vessels of the head. Therefore, a ligature or bandage ought never to be used till such time as the 
opening is made into the vein, and even then it will not be necessary at all times, if the horse can stand on his feet, as a moderate pressure with the finger on the vein will make the blood flow freely; but, if the horse is lying on the ground, a ligature will be necessary.

But farther, the concussion or shock the horse receives from his falling down in the above situation, which will always happen if the ligature is too long continued, may cause a blood-vessel within the head to burst, and death may be the consequence.

Another custom equally absurd, is allowing the blood to fall in a dung-hill amongst straw, in dry sand, or in dry dust, by which means, no distinct idea can be formed of the quantity that is, or ought to be taken away. In such cases, I have seen horses fall down in a faint from the loss of too much blood, before the operator thought of stopping up the orifice.* For this, and a variety of other reasons, which might be mentioned, a measure ought always to be used, in order to ascertain the quantity of blood that is taken away.

* A case of this kind happened in London; a master farrier was the operator 
In pinning up the orifice, some people have a custom of raising or drawing out the skin too far from the vein, hence the blood flows from the orifice in the vein into the cellular substance betiveen it and the skin, which causes a large lump or swelling to take place immediately; this frequently ends in what is called a swelled neck; a suppuration follows, which proves both tedious and troublesome to cure. In cases, when a horse may be tied up to the rack, after bleeding in the neck, pinning up the external orifice may be dispensed with; but, when a horse is troubled with the gripes, or any other acute disease, in which he lies down and tumbles about, it is necessary that the orifice be pinned up with care, in order to prevent the loss of too much blood.

As the neck or jugular vein, on the near side, is commonly opened for conveniency lyy those who are right-handed, the young practitioner should learn to perform on both sides of the neck. This he will find, in practice, to be not only useful, but necessary, as he may frequently have occasion to draw blood from horses in very awkward situations; he will likewise find his account in it in a rariety of cases, which is needless here to particularize.

The proper place for making the opening in the 
neck, or jugular vein, is likewise necessary to be attencied to ; for, when the orifice is made too low, or about the middle of the neck, where the vein lies deep under the muscular teguments, the wound becomes difficult to heal, and frequently ends in a suppuration, with a jetting out of proud flesh from the orifice, which, unluckily, is as unskilfully treated in the common method of cure, \&c. which is, by introducing a large piece of corrosive sublimate into the wound; this not only destroys the proud flesh in the lips of the wound, but a considerable portion of the flesh around it ; and, in farriery, it is called coreing out the vein. It frequently happens, that this corrosive application destroys the vein likewise; I have sometimes seen violent hæmorrhages follow from this cause, insomuch as to endanger the life of the animal.

The most proper place for making the opening in jugular veins, is, where the teguments are thinnest, which is about a hand breadth from the hearl, and about one inch below the branching or joining of the vein which comes from the lower jaw, and which may be distinctly seen, when any pressure is made on the main branch of the vein.

In performing the operation with a fleam, the operator should hold the fleam between the fore-finger 
and thumb of the left hand, with the second finger he is to make a slight pressure on the vein, and, before it becomes too turgid or full, make the opening; the same degree of pressure is to be continued on the vein, till such time as the quantity of blood to be taken away is received into a proper measure.

Another great error, which generally prevails in opening the veins with a fleam, is the applying too great force, or giving too violent a stroke to it, by which it is forced through the opposite side of the vein; hence, there is danger of wounding the coats of the arteries, as they generally lie under the veins, or, in some particular places, of wounding the tendons, especially when this operation is performed in the legs, thighs, \&c. or in the veins, commonly called the plate veins, under the breast, the consequences are frequently very troublesome to remove, and, in some cases, prove fatal; hence, the remedy sometimes proves worse than the disease or lameness it was intended to remove. Mr. Gibson,* in his trea tise on the diseases of horses, mentions a case of a fine horse, that was blooded in the plate veins, for a lameness of the shoulder, which was followed with

* Vol. II. page $18 \%$.

$10 *$ 
a hard oval swelling about the size of a goose əgg, which extended upwards on the breast, and likewise down the leg, attended with excessive pain, fever, deadness in the horse's looks, and all the other symptoms of a beginning mortification. I could likewise add a number of similar cases, which have fallen under my own inspection, but shall not trouble the reader with them at present.

In order to avoid the consequences sometimes attending these local operations in the breast, legs, \&c. and, as horses are more or less troublesome and restless, whereby accidents of this kind may happen, it will perhaps be adviseable, in most cases of lameness, \&c. to draw blood from the larger veins in the neck only, where there is less danger of accidents, more especially if a spring fleam is used; for, although it might be of some advantage, in particular cases, to draw blood as near the affected part as possible, yet the bad consequences frequently attending it, ought to counterbalance any advantages that may be expected from it, especially as the quantity of blood drawn from the small veins is but inconsiderable, and, of course, no great benefit can be expected from it in horses when they are diseased. 
The principal view, in drawing blood, is the lessening of its quantity, by which the remaining mass circulates with more freedom in the vessels; it likewise takes off the inflammatory tendency of the blood, it removes spasms, \&c. and prevents other bad consequences that may follow, especially in plethoric habits; and it ought always to be remembered, that, when the signs or symptoms of a disease are taken from the motion of the blood, the disorders arising from it depend upon its circulation being either increased or diminished; hence, therefore, all the changes which take place in the texture, quantity, and quality of the blood, are attended with a diminution or increase of its velocity.

Although the cases which may require bleeding are numerous, yet I would recommend one general caution, which is, never to take away blood but when it is absolutely necessary; for it is a fluid that may be easily taken away, but cannot be so easily replaced; besides, the practice of blceding frequently, or at stated times, is exceedingly improper, as it disposes the body to become lax, weak, and plethoric. 
In bleeding, therefore, a due regard must always be had to the constitution, age, strength, \&c. of horses, and the state or habit of body they are in at the time.

It is commonly said, that the taking away a little blood from horses, even when they are in health, or when they are in the least indisposed, will do no harm; this, in one sense, may be allowed to be literally true, but why draw blood from them on every trifling occasion, unless there may be such symptoms attending as may require it. I have observed in many horses who have been very frequently blooded, and which may be easily known, from the cicatrices or marks on the neck-veins, that their blood was poor and thin, and had lost that tenacity peculiar to rich blood, together with a considerable portion of its florid and red colour. Butchers who slaughter calves, may find their account in bleeding them frequently, as it renders their flesh white, by taking away the red particles of the blood. But in horses it is quite otherwise, as they are destined for hard labour and active exercises, it impairs their constitutions, subjects them to diseases, and hastens a premature oid age. 
As the blood of horses, more especially those who are constantly employed in hard labour, or in active exercises, when drawn from a vein, appears of a darkish or deep red colour even in the highest state of health, it is commonly said to be bad blood, and more so, when a thick yellow or buff-coloured crust forms on the surface after it is cold; hence these appearances are said to require a repetition of bleeding; for it very unluckily happens, that most of the diseases to which horses are subject, are thought to proceed from some impurities or humours, as they are called, in the blood, which require to be drained off by bleeding, and other evacuations.

With regard to any information that may be drawn from the appearance of the blood when cold, it will be found, that no certain conclusion can be formed from it, since blood that is drawn from a horse who is evidently disordered, will sometimes have the same appearance, when cold, as that drawn from a borse in health. On the other hand, blood drawn from a horse in health, will sometimes have all the appearance of that drawn from one labouring under the most dangerous disease; and this may depend on so many concurring causes, that renders it difficult to fix any precise standard how we may judge, eith- 
er of the healthy or morbid state of the blood in horses when cold; as its appearances are even affected by the manner in which the operation of blood-letting is performed, and that of the blood's being received into the vessel.

When blood is drawn from a vein of a horse that is in health, it appears to be an uniform fluid of a red or darkish colour; but, after it has been exposed to the cold air, \&c. it coagulates into a stiff mass, which gradually separates the thinner parts into a pellucid serum, the thicker parts into a red or darkish mass, which is called the crassamentum.

Although I am thus sparing of drawing blood from horses on trifling occasions, when they may be said to be in health, yet when cases occur that do require it, I would recommend the taking away a greater quantity at once than is generally done, that is, from six to eight pounds, which will be about three or four quarts English measure, according to the urgency of the symptoms, \&c. at the time, the strength and age of the horse considered. For, as horses are very subject to inflammatory diseases, and those that are of the spasmodic kind, and as bleeding plentifully relaxes the whole system in these cases, the taking away a small quantity of 
blood, about one quart, or two pounds, is in fact trifling with the disease; the horse is said to have been blooded, that satisfies his owner and the farrier; time is lost; the disease acquires strength, it will then be beyond the power of art to mitigate or to conquer it; hence the horse falls a sacrifice to timidity and ignorance. It is to be remembered, that, in inflammatory diseases, (particularly when the bowels are affected) that they make a very rapid progress in horses, and, if they are not overcome at the beginning, by bleeding plentifully, the horse commonly dies, in twenty-four or thirty hours, of a gangrene and mortification in the intestines. I have seen so many cases of this kind, and which have been confirmed on dissecting the bodies afterwards, that I cannot be too full on the subject, in warning practitioners how they should act in such cases; and, perhaps, few occurrences in practice gave me more uneasiness than to be consulted in the last stage of these complaints, when nothing could be done for the relief of the horse.

The quantity of blood here recommended to be taken away at once, may, by many people, be objected to: In answer to which, I would observe, that, in inflammatory cases, I have always found the greatest benefit from it in practice. 
The blood is a fluid of a peculiar nature; it is the great fountain of life, and the source of all the humours in the body; it circulates through, and nourishes every part of the animal system, being conveyed from the heart by the arteries to the extremities and surface of the body, and returned to the heart again by the veins. This circulation is so complete, that the most trifling wound or scratch is immediately followed with a discharge of blood from the sinall capillary vessels of the skin. In order to explain more fully how the circulation is performed, it will be neccssary to give a short description of the heart, the arteries and veins, with some general remarks on the pulse of horses.

The heart is a muscle of a conic figure, that is; broad at its basis, and terminating in a blunt apex or point; it has four cavities, two of which are called auricles or ears, and the other two ventricles. The auricles are situated at the basis of the heart, and receive the blood immediately from the veins; the right from the vein called vena cava, and the left from the pulmonary vein; at the bottom of these auricles, are certain valves which open into the ventricles, and shut again when the latter are filled with blood, in order to prevent its return to the auricles: Thus, when the right 
rentricle receives the blood through its auricle, the valves shut, and the blood is forced by the contraction of the heart, from the ventricle into the pulmonary artery, which rises immediately out of the right ventricle, and is carried into the lungs; it is returned from thence by the pulmonary veins into the left auricle, which empties itself into the ventricle on the same side, and by it the blood is forced into the great artery or aorta, which rises out of that ventricle, and which conveys it all over the body; the blood is returned to the heart by the veins (which, in their course, take in the chyle or noursshment) to the right auricle of the heart, which completes the circulation.

'The heart is fixed at its basis, by the vessels, \&c. which belong to it, and to the mediastinum, \&c.; it is contained in a bag or purse, called the pericardium, within which there is a small quantity of a clear watery lymph, separated there by the exhaling vessels, that the surface of the heart may not grow dry from its continued motion; the heart is supplied with nerves and blood-vessels for its own nourishment.

The arteries are conical tubes or pipes, which convey the blood from the heart to all the parts of the body ; they posses a very elastic quality, by 
which they contract and dilate themselves, according to the impulse of the blood, which is propelled or forced into them by the heart; 'I his contraction and dilation of the arteries is called the pulse, and which takes place in all the arteries at the same instant of time; for, as the left ventricle throws out the blood into the arteries, they are dilated, and, as soon as the elasticity of the arteries can overcome the impulse of the blood, they are again contracted; hence these two causes, viz. the action of the heart, and the elasticity of the arteries, operating alternate$1 y$, keep the blood in a continual circulation.

'The arteries being conical canals, are large at their origin, and gradually diminish towards their. extremities (resembling the trunk and branches of a tree) where they anastamose, or join with the extreme branches of the veins; hence, the latter may be said to be a continuation of the arteries.

The veins, as 1 have just now mentioned, are a continuation of the extreme capillary arteries reflected hack towards the heart, uniting their channels or branches as they approach it, till at last they form the larger veins; hence, they may be said to resemble the brancles and trunk of a tree, inverted from the extremities to the heart. There 
is no pulsation in the veins, because the blood is thrown into them in a continued stream from a narrow channel to a wider.

In most of the veins where the blood rises in a perpendicular column, as in the legs, \&c. there are valves which open towards the heart, and admit the blood to pass freely; but it cannot fall back or repass these valves; therefore, if it is not pushed on with sufficient force, it may distend the veins, and cause a swelling of the legs. Hence it is observed, that this lentor or sluggish circulation of the blood in the leg-veins, is remored, and the circulation greatly forwarded, by muscular motion, or, in other words, by exercise.

The veins, for the most part, accompany the arteries; hence, when a vein must be opened, it is to be remembered, that an artery is near, and, frequently, immediately under it, as large as the vein itself, (and which may be easily distinguished by its pulsation;) and hence the coats of the arteries are liable to be wounded by an unskilful operator in drawing blood. The extreme branches of the arteries and veins have numerous communications with one another, resembling the fibres in the leaves of plants, by which communications, the blood, when 
obstructed from any cause in the branchings of these vesseis, may pass through by other channels that are not obstructed; this likewise takes place when the larger vessels are divided; the circulation is continued by the detached branches of the remaining veins.

These remarks being premised, it remains to make some observations on the pulse of the arteries in horses, a due attention to which is of the utmost consequence to practitioners in farriery, and which, in the general practice, seems either to be not understood, or not attended to ; for, without a proper knowledge of the pulse, we neither can form a right judgment of diseases, in which the vascular system is affected, the velocity of the blood increased or diminished, neither can we judge rightly when it is necessary to let blood, nor to refrain from it. It will therefore be proper, first to consider the pulse in a healthy state, before we can form a just idea of it when a disease takes place.

The pulse of a horse that is in health, and nowise terrified or alarmed, is from thirty-six to forty beats in a minute; it may ensily be felt by pressing the fingers gently on the temporal artery, which is situated about an inch and a half backwards from the upper 
corner of the eye. It is necessary to observe, that, if the fingers are pressed too hard, (as the bone or scull lies below the artery,) no pulsation will be felt, as ton great pressure stops the circulation in the artery at the time. It is likewise necessary to observe, that the pulse of a horse, about thirteen or fourteen hands high, is quicker than one of a larger size. When a horse is in great pain, or in a violent fever, the pulse will be raised from eighty to one hundred beats in a minute, and sometimes considerably above it.*

The pulse in a healthy state, is equal, moderate, and free, which shows, that the heart and vascular system in general are firm and vigorous, and that the heart empties itself freely at each contraction and dilation, that there is no impediment to the passage of the fluids, through the viscera and vessels, and

* It is necessary to observe here, that the pulse of young animals are quicker than they are as they advance in life, and that, in old age, they gradually decrease in fiequency. If the pulse of a middle aged horse, much exceeds forty-five strokes in a minute, some infammatory disorder must be the cause. If much slower the horse is labouring under debility. Exercise increases the frequency of the pulse in all animals. The proper time therefore, to examine the pulse of a lorse, is not until after he has been at rest, some hours at least.-Ar. ED. 
that the nerrous power acts uniformly upon every part of the circulating system. Whereas, in a morbid or diseased state, it will be unequal and intermitting every now and then, varying in the time between the strokes, as well as the force of the stroke; sometimes it will stop entirely, and sometimes it will be immoderately quick, at others unnaturally slow; sometimes it will be raised greatly abore the healthy degree of strength, and at others sunk as much below it. This unequal or intermitting pulse, shows, that the nervous system is greatly disordered, and portends great danger, especially if it becomes so after long illness, when the strength is much exhausted.

When the pulse beats strong and quick, it shows, that the morbid or diseased stimulus, excites the heart to expel the blood, with great force, and that the progressive motion of the blood is more rapid and impetuous than it ought to be; as this strong pulse strains and speedily exhausts the vital powers, it portends great danger, if not soon removed.

The hard, quick, and strong pulse, is generally a symptom of considerable irritation, and shows, that the heart is greatly stimulated; this takes place in inflammations of the viscera, as in peripneumony, or inflammation of the lungs, stomach, intestines. 
The hard, quick, low, or sma!l pulse, shows great inward pain, which, by sympathetically affecting the heart, excites it to empty its ventricles before they are sufficiently filled with blood.

A quick pulse is generally a sign of a fever; when it is exceedingly quick and weak, it is always a very dangerous symptom, as it shows, that the porvers of the heart are nearly exhausted, and that, in order to support the circulation, it is forced to act more frequently, and to empty its ventricles by a number of weak contractions.

When the pulse beats soft and weak, it may be owing to a general laxity of the fibres of the arteries, or to a thin watery state of the blood, which enables it to glide too easily through the ressels, that the heart is not under the necessity of exerting so much force in propelling it through the arteries, as when they are more firm or unyielding, or when the blood is more dense or viscid, which are great impediments to a free circulation in particular organs.

A weak pulse is a sign either of a considerable debility or weakness of the heart, or ton small a quantity of blood in the ressels in general, or some impediment to-the influx of the blood into the heart, 
or to some, or all of these causes combined; for this reason, it is to be met with frequently in low fevers, or towards the end of diseases that prove fatal.

When the pulse remains full under the fingers during the contraction and dilation of the arteries, it is a sign of too great fulness of the vessels, either from a plethora, or too great a rarification of the fluids, by febrile, heat, or other causes; it indicates danger from accumulation, distension, and even rupture of some of the blood vessels in particular organs. But, if the pulse, though full, is at the same time soft and distinct, it is a favourable symptom, as it shows, that there is no considerable constriction in the vessels.

Upon the whole, the pulse is always bad when it is very different from its natural state ; for, as a weak and quick pulse shows debility in the heart and vascular system, regard at the sane time being always had to other symptoms, if the pulse sink in fevers there is great danger.

On the other hand, when the pulse is equal, regular, and moderately full, especially if it becomes so from being languid, weak, and irregular, on the breaking out of some critical discharge. as that of sweat or iooseness, or the staleing frequently, it is a sign of amendment. 
From what has been observed, it will be obvious, that the information to be attained from a due attention to the state of the pulse in the diseases of horses, is of cunsequence in the practice of farriery. Young practitioners ought therefore to make themselves well acquainted with all the variations that take place in diseases, together with the changes that happen when deviating from the healthy state to the morbid or diseased.

It may be necessary again to observe, that, in feeling the pulse of a horse in health, that he be not frightened, nor anywise alarmed, as that will make an alteration in the quickness of the pulse, which will be apt to mislead the unexperienced.

Thus much may suffice at present concerning the pulse in general ; it will be necessary to be more particular when the signs to be taken from it are applied to particular diseases, and corroborated by other symptoms, I shall therefore proceed to enumerate the different cases that may require bleeding.

The cases which may require bleeding, are in all violent bruises or strains in the muscular or tendenous parts; in large wounds, especially when there is a laceration or tearing of the parts without much 
loss of blood from the wound; in the beginning of all cuticular disorders or eruptions on the skin, as little pustules, dry scabs, \&c.; in large swellings on the body or legs; in all deep punctures, or small wounds, when the horse shows symptoms of great pain, \&c.; in swellings of the legs and beels, from inflammations, \&c.

Bleeding is necessary in most diseases where great sickness prevails, and is the speediest method of giving relief in the beginning of inflammatory fevers, to which horses are very liable; it is also necessary in all violent acute pains, as in the gripes or cholic, strangury or suppression of urine; in rheumatic complaints, where the stiffness or lameness shifts from one limb to another, or when it affects the neck, and causing great stiffness, which is commonly called the chords; in inflammations of the eyes, or palate of the mouth, which is called the lampars, when the horse cannot eat his food on account of the tenderness of the parts; in all recent colds, attended with rheums or defluctions about the throat, eyes, \&c.; in recent sivellings of the glands about the throat, jaws, \&c. ; in the jaundice, inflammations of the lungs, pleura, stomach, intestines, and other viscera; in apoplexy, vertigo, or giddiness; and in 
all disorders where the head seems affected; in the beginning of impost humations, or collections of matter in any part of the body, attended with great pain; in plethoric or full habits of body, where proper exercise has been long neglected; and when a horse becomes bieathless on the least exercise.

On the other hand, bieeding is to be avoided, unless in very urgent cases, in all extremes of very hot or very cold weather, and whilst a horse is overheated from violent exercise; in all cases of extreme lowness of body, or weakness, throngh fat yue, disense, scc.; after all evacuations by purging or scouring, diabetes, or profuse staleing, loss of blood, from great wounds, or profuse sweating. Bleeding is likewise to be avoided, when imposthumations, or collections of matter is once formed properly in any part of the body; likewise during the time horses are moulting in the autumn.

Thus, I have endeavoured to show the principal cases where bleeding is necessary, and likew:se where it ought to be avoided; no doubt particular cases and accidents may, besides those above mentioned, happen, when bleeding may be necessary, but these, from what has been said upon the subject, will readily occur to the judicious practitioner. 


\section{CHAP. XX.}

\section{A CONCISE VIEW OF THE ANATOMY OF} THE FUUT.

\footnotetext{
'The font of the Horse developes a curious, complicated, and beautiful structure. It comprises all that portion from the coffin-joint downwards; and for the sake of perspicuity, is generally divided into the internal and external foot.
}

\section{INTER N A L FOOT.}

The internal foot of the horse is composed of various sensible parts, appropriated to different purposes. It comprises in the first place, the navicular and coffin-bones. 'T'se navicular-bone constitutes 
the posterior part of the coffin-joint, and is connected to the pastern, and coffin-bones, by ligaments. The coffin-bone is the lowest, and last bone of either extremity. These two bones are the base and support of the column of bones above, and act as pullies to those tendons which are inserted into the foot. Their union serves to prevent concussion when the limb is in motion.

The internal foot comprises in the next place, a portion of those tendons that enter the foot for insertion ; a considerable quantity of fatty substance situated behind the back tendons, and serving as a soft and elastic cushion for those tendons to act, or rest upon; also two thin cartilages growing out laterally from the coffin-bones, which help to prevent concussion and keep the heels of the foot expanded; the sensible frog and sole; and lastly a sensible laminated substance. covering all the anterior and lateral parts of the internal foot, which being received into corresponding laminæ on the internal surface of the crust, support the whole weight of the animal. This has been proved by removing the horny sole, frog, and bars, (constituting the bottom of the foot) when the crust was found sufficient to sustain the horses weight. These laminæ possess great elasticity, and afford to 
the foot a most curious and complicated spring. The internal foot secretes the external hoof; in other words, the external horny hoof grows from the internal sensible foot; consequently the internal foot must necessarily be supplied with numerous bloodvessels and nerves, which render it highly sensible and easily inflamed. Any contraction of, or undue pressure upon, the horny hoof is propagated to the internal sensible foot, and interrupts its functions; consequently pain, disease and lameness follow.

\section{EXTERNAL FOOT.}

The external foot, or horny hoof is intended to enclose, and protect from injury the internal vascular and sensible foot. It is composed of a hard, elastic, but insensible substance, very durable, and admirably calculated for the purpose for which it was intended. It consists of the wall or crust, the sole, the frog, and the bars. The upper part of the crust, where it is connected with the skin, is called the coronet. The lower part in front, the toe; the sides of the crust are named the quarters; the quarters terminate in the heels; and the heeis are connected with the frog. 'The crust descends from the coronet to the base (in a well formed foot) in a re- 
gular slope, at an angle of about forty-five degrees, giving to the hoof somewhat of a conical figure.

The inside of the crust is almost entirely covered with a beautiful set of laminæ, which very much resemble the under side of a mushroom. These are received into, and united with similar laminæ, situated on the outer surface of the internal sensible foot, and constitute a most powerful spring, to the horse in motion. The number of laminæ situated on the inside of the crust, has been computed at about five hundred, in a middling sized borse. The outer surface of the internal foot contains an equal number to receive them. Each laminæ or fold has two sides and an edge ; making three surfaces of union to each laminæ. Consequently one foot of a middling sized horse has three thousand points of union; giving to it a surface of about four square feet. Now as a horse has four feet, and as each foot has a surface of bearing of about four square feet, it follows that a horse treads on sixteen square feet, instead of as many inches, as might naturally be supposed. It has been stated above that the attachment or union between the folds or laminæ on the inner surface of the external foot or crust, and the folds or laminæ on the outer surface of the internal foot, are equal to 
the support of the weight of the animal, when the horny hoof, sole, frog and bars are removed. This proves pretty clearly that the crust was intended to support the weight of the horse, and not the frog, as some bave believed. Professor Coleman founded his system of shoeing upon the idea that the frog ought constantly to press upon the ground and support in a great measure the weight of the animal. I may at some future period give an opinion upon this subject, but at present 1 shall pass it over by remarking that $I$ am informed from a source that may be credited, that Mr. Coleman's system is not now practised at the Veterinary College, where he is Professor and principal Director, nor in the Cavalry where he is the first Veterinary Surgeon. It would seem therefore that experience has not proved its practical utility. 


\section{EXPIANATION OF THE PLATES.}

\section{PLATE I.}

Fig. 1.--Represents part of a fore-leg, with a side view of the foot, shod on Mr. Goodwin's system.

a.- Shows the shoe on a straight line from the heel to the point of curve, and also the degree of curve at the toe.

$b$, \&c.-The parts where the nerve operation is usually performed.

Fig. 2.-A side view of the coffin-bone.

a.- - Shows the degree of curve at the toe, in the natural bone, and harmonising with the French method of shoeing. 
PLATE. II.

Fig. 1.-Natural hoof.

a.-French method of driving the nails within the crust, and going through a portion of the sole.

Fig. 2.- Contracted hoof.

Fig. 3.-Convex sole, or pumiced hoof.

Fig. 4.-Flat thin hoof, with weak low heels.

Fig. 5.-Natural coffin-bone.

Fig. 6.-Coffin-bone after some years shoeing.

PLATE III.

Fia. 1.-Patten shoe.

Fig. 2-Screw shoe.

Fig. 3.-Bar shoe, the foot side, with the bar raised.

FIg. 4.-Plain bar shoe, the foot side.

Fig. 5.--Road shoe, with moveable toe-pieces.

Fig. 6.-Frost shoe, with moveable ruffs.

$a, a, a .-$ Degree of curve at the toe. 
PLATE IV.

Fic. 1.-Mr. Goodwin's shoe, the ground side.

Fig. 2.-Ditto Ditto, the foot side.

FIG. 3.--French horse nail.

Fig. 4-Straight line from the heel to the point of curve at the toe, with the degree of curve.

\section{PLATE V.}

Fra. 1--Speedy cut boot.

Fig. 2.--Swab.

Fig. 3.-Water boot.

FIG. 4.-Bottom for water boot.

Fig. 5.-Rope boot. 

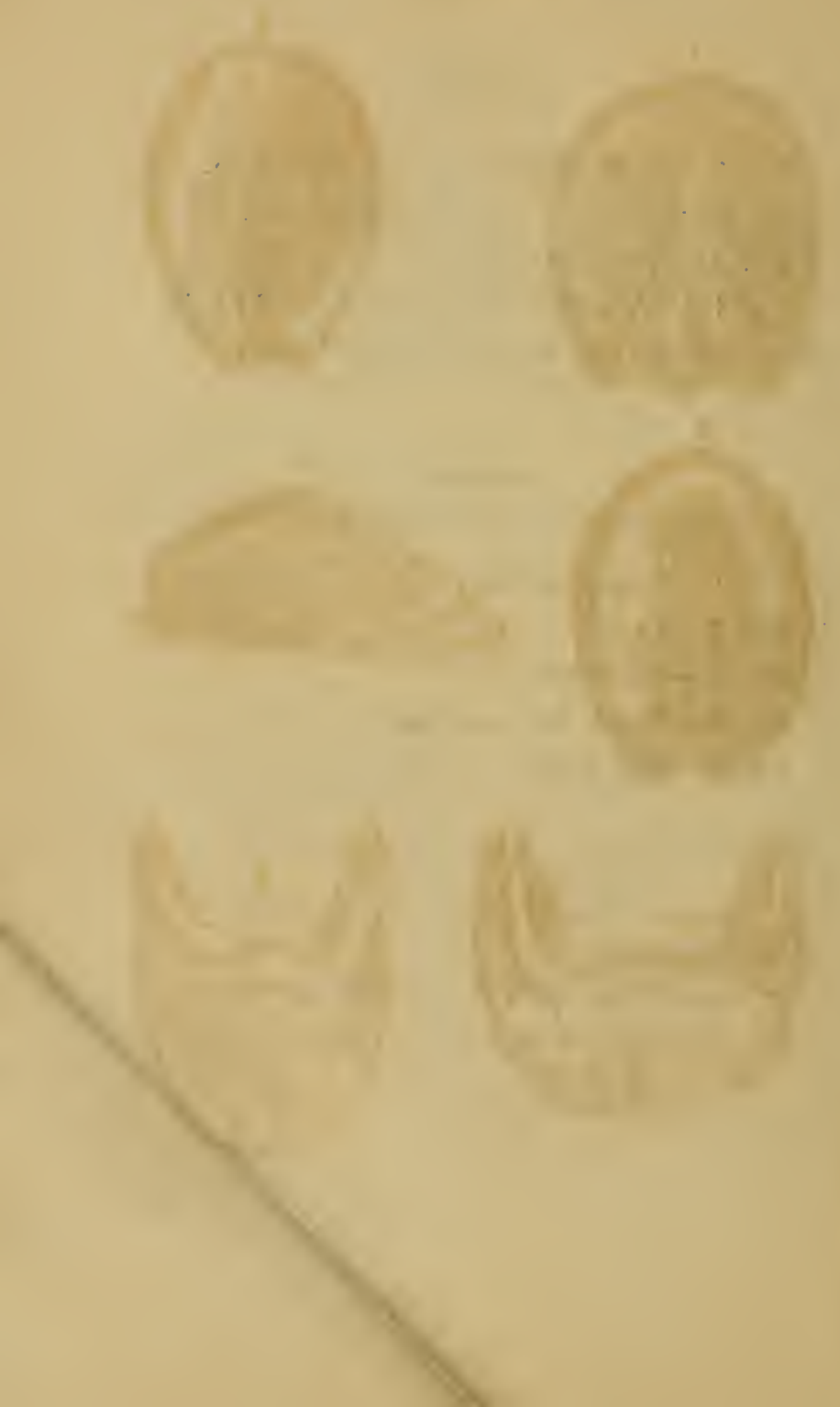


\section{PLATE II.}
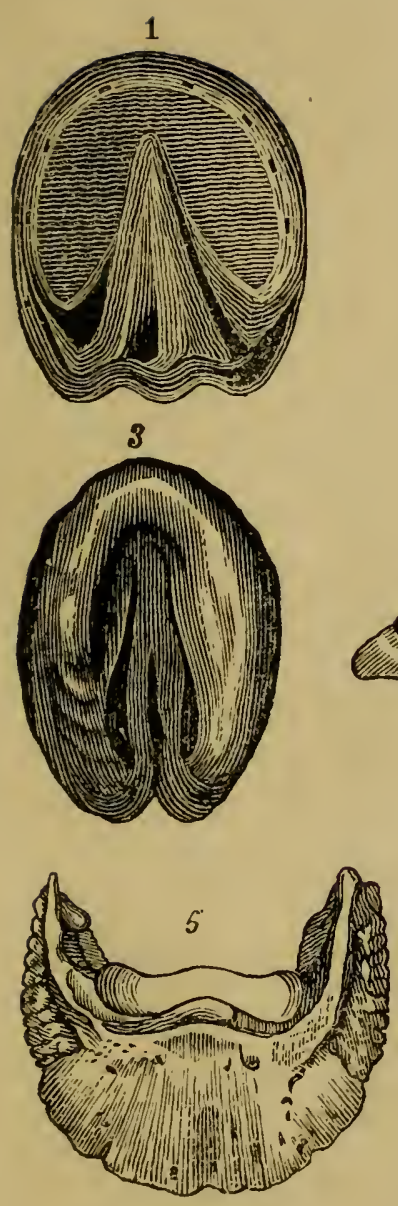
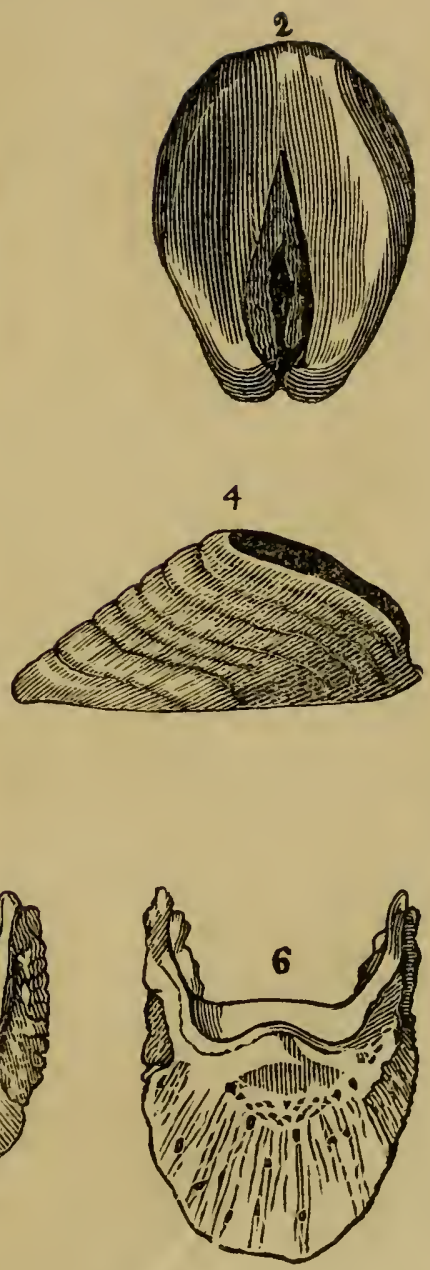


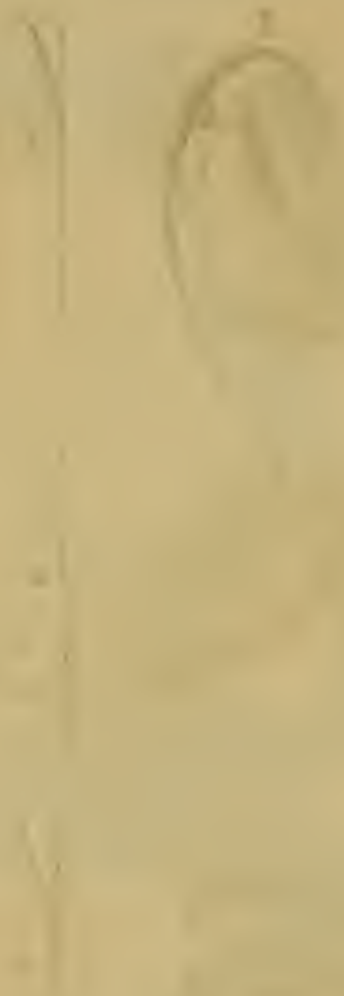

$$
2
$$
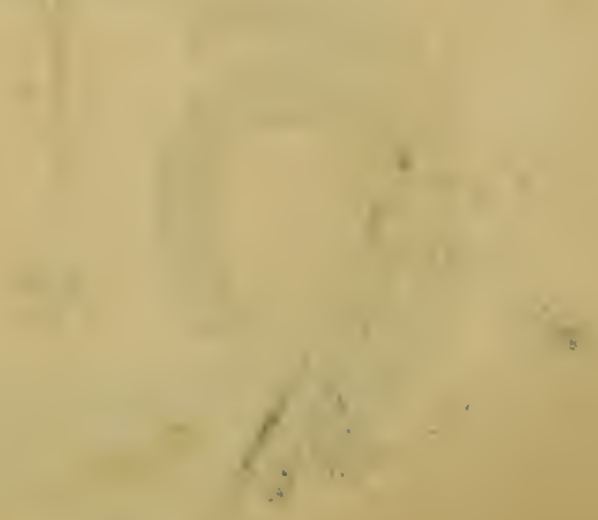

(n) 
PLATE III.
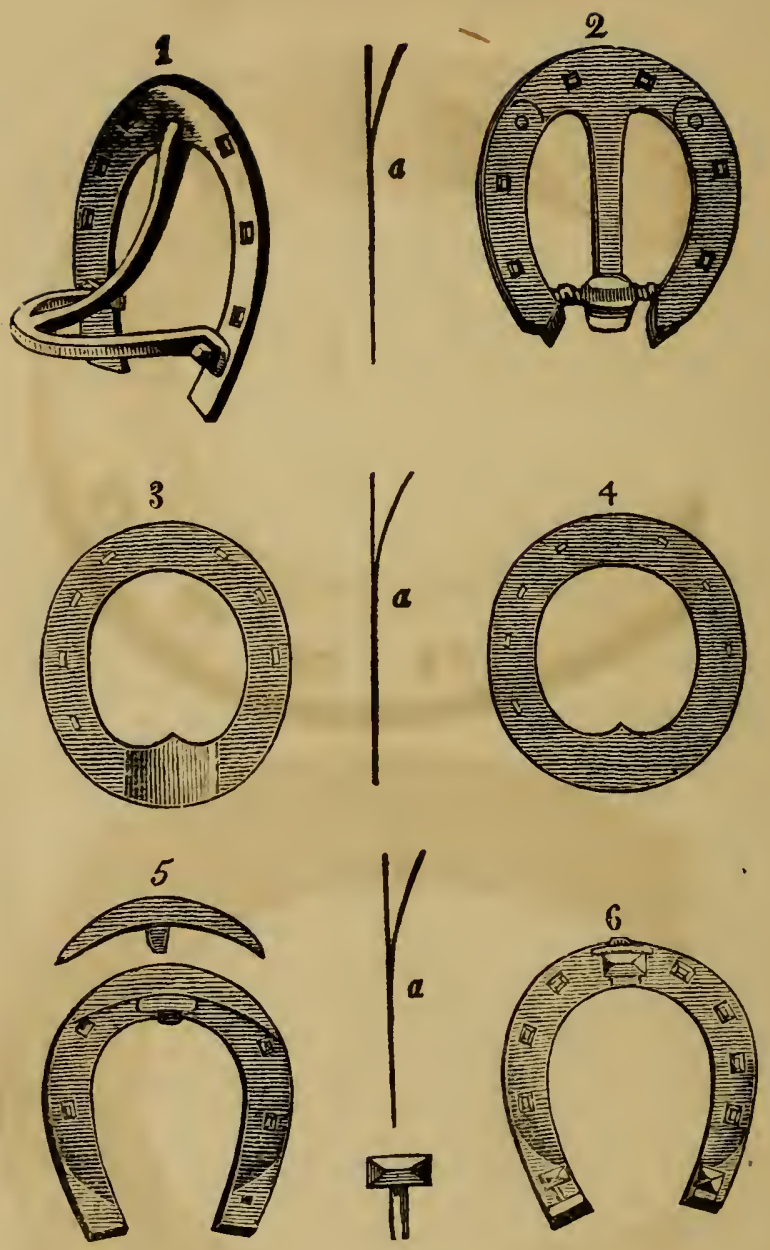
PLATE IV.
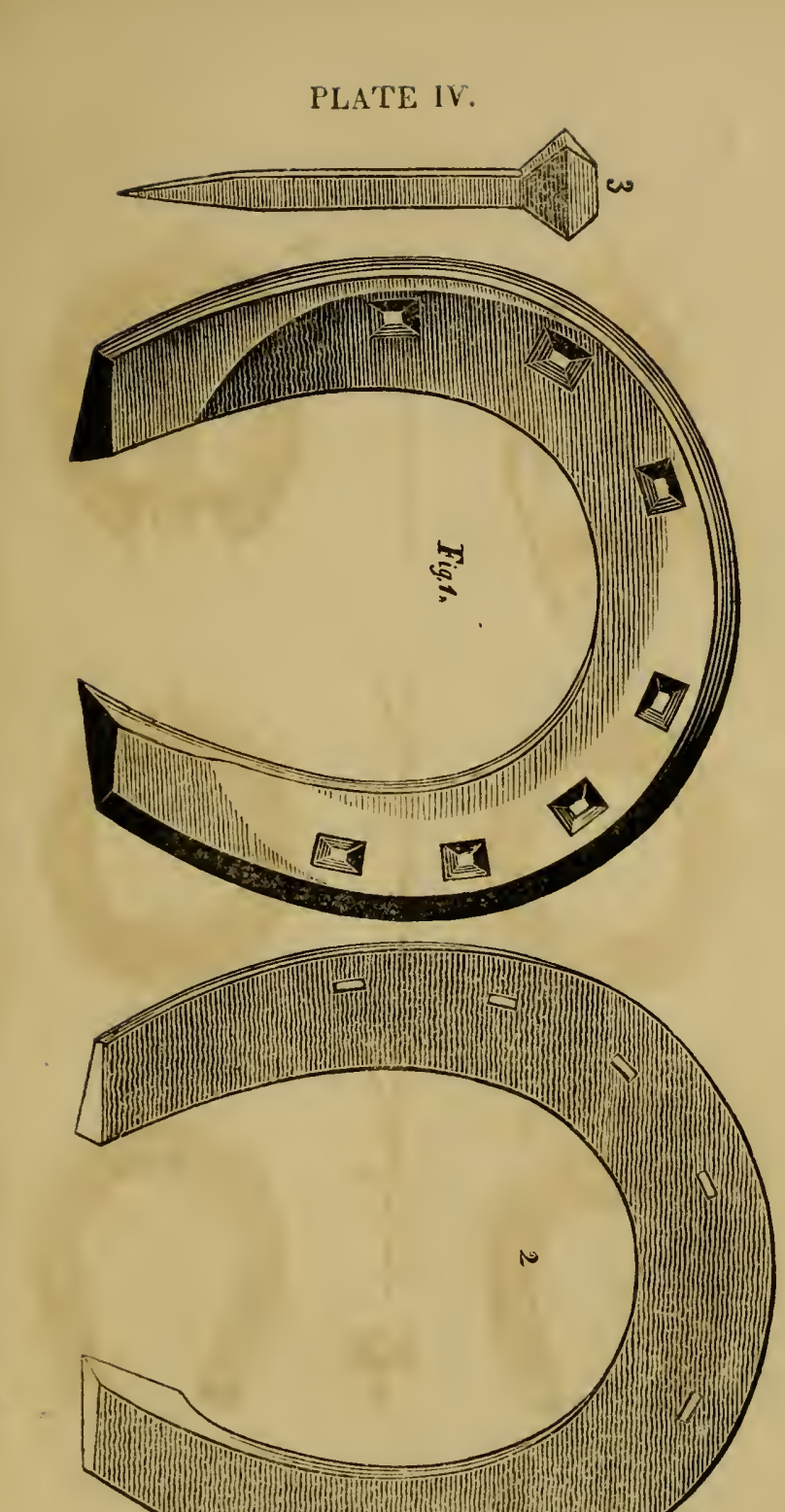
.

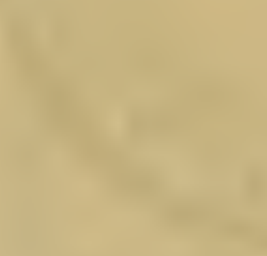


$=$ 
PLATE $V$.
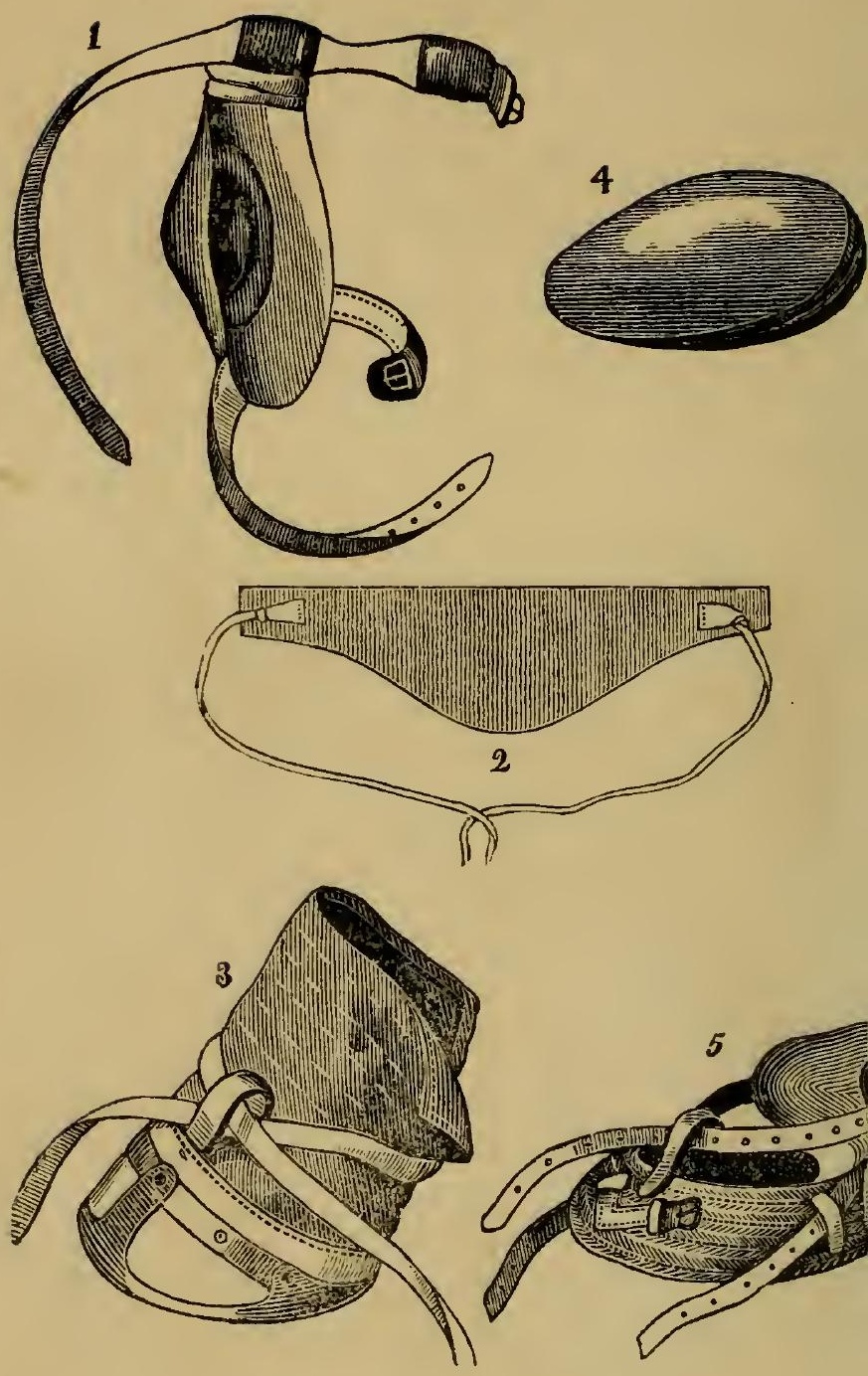



\section{$\omega_{7}=4+4$}

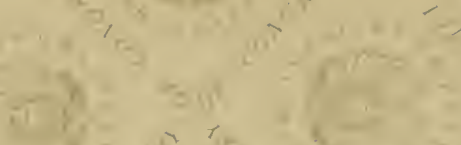

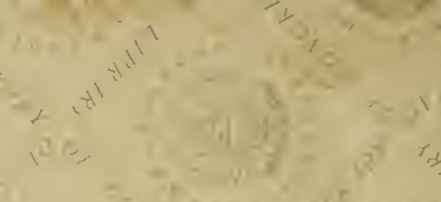

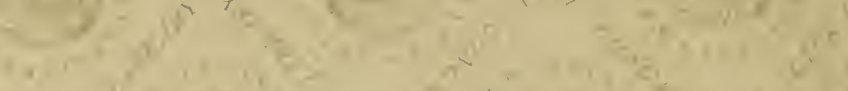

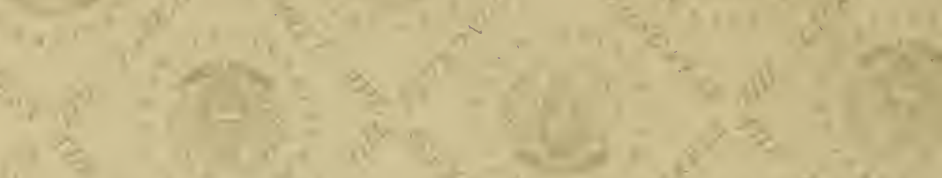

$a x^{2}+x^{-2}$

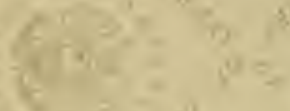

$x^{2}=$

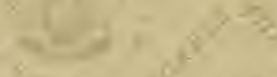

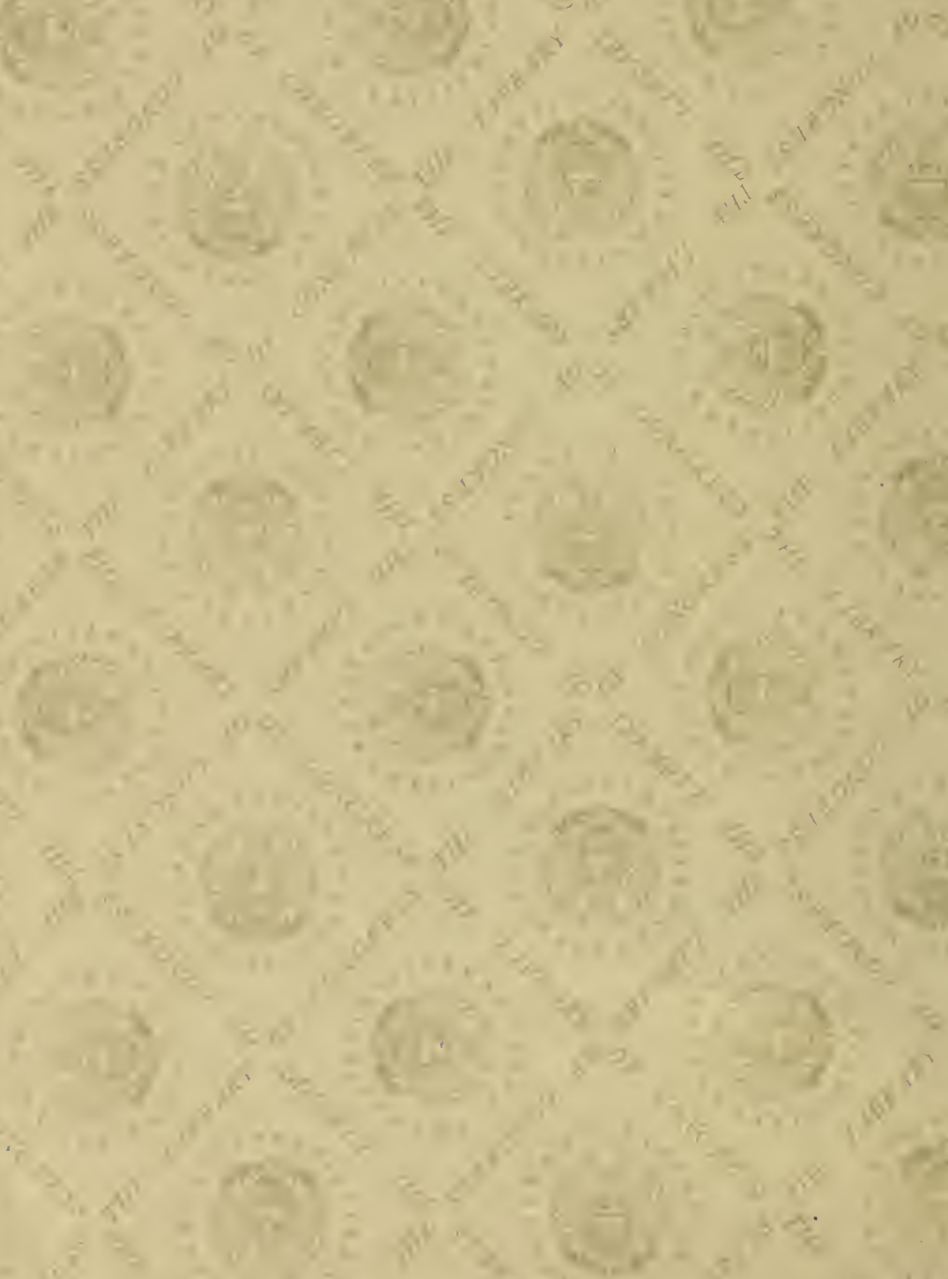




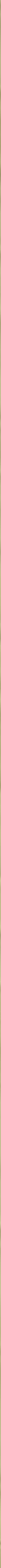


LIBRARY OF CONGRESS

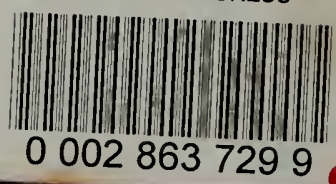

